\title{
Photovoltaic Power System with an Interleaving Boost Converter for Battery Charger Applications
}

\author{
Sheng-Yu Tseng ${ }^{1}$ and Cheng-Tao Tsai ${ }^{2}$ \\ ${ }^{1}$ Department of Electrical Engineering, Chang-Gung University, Taoyuan 33302, Taiwan \\ ${ }^{2}$ Department of Electrical Engineering, National Chin-Yi University of Technology, Taiping 411, Taiwan
}

Correspondence should be addressed to Cheng-Tao Tsai, cttsai@ncut.edu.tw

Received 20 June 2012; Accepted 11 September 2012

Academic Editor: Tapas Mallick

Copyright ( $) 2012$ S.-Y. Tseng and C.-T. Tsai. This is an open access article distributed under the Creative Commons Attribution License, which permits unrestricted use, distribution, and reproduction in any medium, provided the original work is properly cited.

\begin{abstract}
This paper proposes a photovoltaic (PV) power system for battery charger applications. The charger uses an interleaving boost converter with a single-capacitor turn-off snubber to reduce voltage stresses of active switches at turn-off transition. Therefore, active switches of the charger can be operated with zero-voltage transition (ZVT) to decrease switching losses and increase conversion efficiency. In order to draw the maximum power from PV arrays and obtain the optimal power control of the battery charger, a perturbation-and-observation method and microchip are incorporated to implement maximum power point tracking (MPPT) algorithm and power management. Finally, a prototype battery charger is built and implemented. Experimental results have verified the performance and feasibility of the proposed PV power system for battery charger applications.
\end{abstract}

\section{Introduction}

Due to the continuous growth of the global energy demand for developing industry, it increases society awareness of environmental impacts from the widespread utilization of fossil fuels, leading to the exploration of renewable energy sources, such as PV arrays, wind energy, and so on. One of these sources is PV arrays energy, which is clean, quiet, and maintenance-free. However, due to the instability and intermittent characteristics of PV arrays, it cannot provide a constant or stable power output. Thus, a power converter ( $\mathrm{dc} / \mathrm{dc}$ converter or $\mathrm{dc} / \mathrm{ac}$ converter) and MPPT algorithm are required to regulate its output power.

Several MPPT algorithms have been proposed [1-10]. Some of the popular MPPT algorithms use perturbationand-observation method [1-3], incremental conductance method [4], constant voltage method [5, 6], $\beta$ method [7], system oscillation method $[8,9]$, and ripple correlation method [10]. The perturbation-and-observation method requires the measurement of only a few parameters, thus it facilitates an MPPT control. As a result, it is often applied to the PV arrays for enhancing power capacity.
A typical PV power system is shown in Figure 1. The PV arrays usually need a battery charger to increase its utility rate. The research of this paper is only focused on PV arrays for battery charger applications. For charger design, many charging methods have been developed, such as the constant trickle current (CTC), constant current (CC), constant voltage (CV), hybrid CC/CV [11], and reflex charging methods [12-15]. The CTC method has a disadvantage that it has a longer charging time, the CC and $\mathrm{CV}$ are the simplest methods to battery charger, but both of them result in the situations of undercharge and overcharge. The hybrid CC/CV method can improve charging efficiency and charging time, but it has a disadvantage of difficult control. To reduce the charging time of the batteries, the reflex charging method is adopted in this paper. The method consists of a high positive pulse-charging current followed by a high current, short time negative pulse-discharging current, and a rest period. A high positive pulse-charging current can reduce the charging time and a negative pulsedischarging current is to reduce internal cell pressure and temperature of batteries. A rest period can provide the batteries with a reflex time in charging process. 


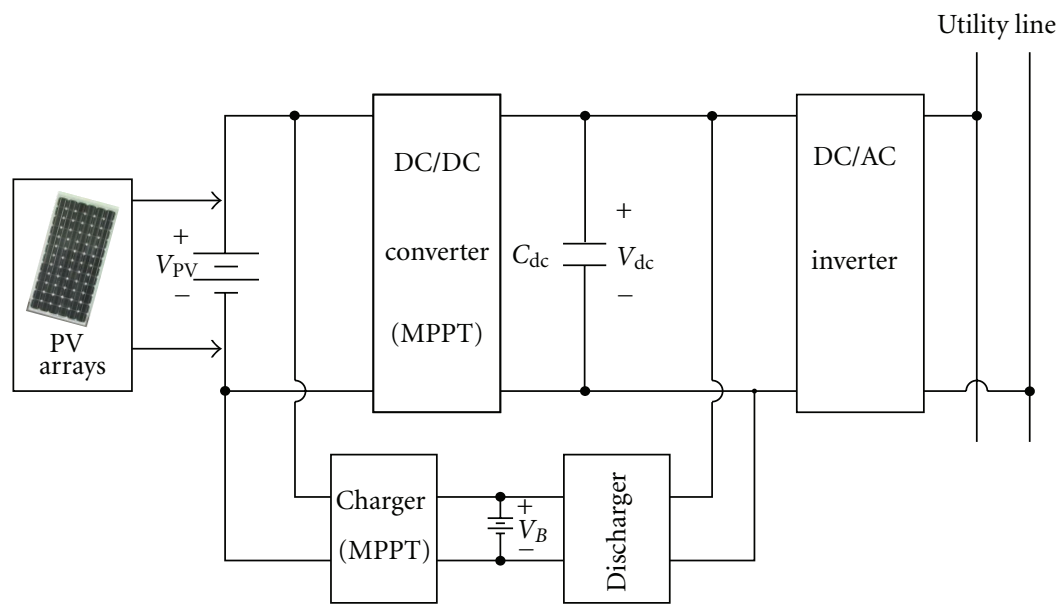

FIGURE 1: Block diagram of a typical PV power system.

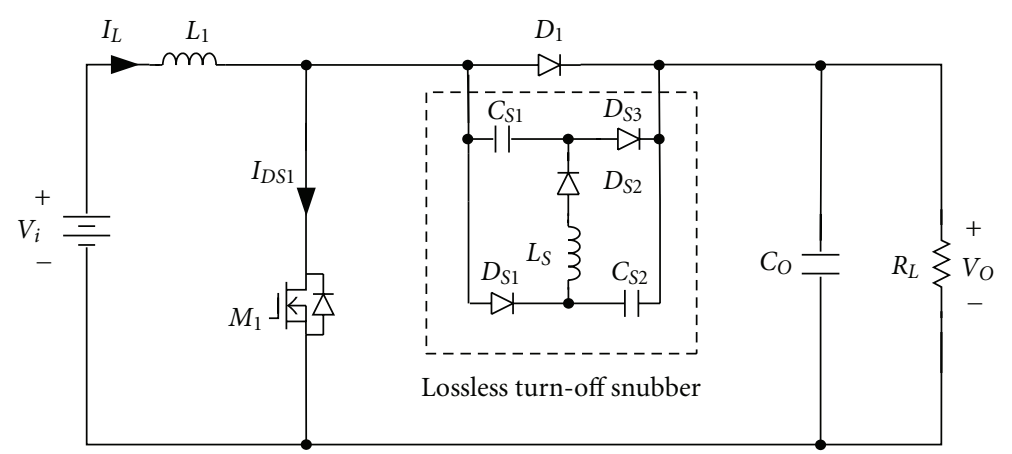

FIGURE 2: Topology of basic boost converter with a passive lossless turn-off snubber.

The basic switching power converters have six circuit structures, such as buck, boost, buck-boost, Cuk, Sepic, and Zeta converters. In order to obtain continuous input current for battery charger, the basic boost converter is widely used. However, it is operated under high switching frequencies resulting in high switching losses, noises, and component stresses. These drawbacks reduce power seriously and deteriorate in the performances of the basic boost converter. In order to alleviate the problems described previously, soft-switching technologies are introduced into the basic boost converter to reduce switching losses. Softswitching technologies can be classified as passive and active soft-switching technologies. The passive technologies use only passive components to perform soft-switching operation [16-18]. The active technologies add one or more active switches along with other passive components to the basic switching power converters to perform soft-switching operation $[19,20]$. For cost considerations, the proposed battery charger with passive soft-switching technologies is more attractive at low power level applications.

A basic boost converter with a passive lossless turn-off snubber for battery charger applications is usually adopted, as shown in Figure 2 [18], because it has a simple structure. However, the basic boost converter has a disadvantage that its output ripple current will swing over a wide range resulting in a low battery life. In order to reduce output ripple current and increase power level, two sets of boost converters are incorporated with an interleaving fashion, as shown in Figure 3 [21]. Although interleaving boost converter with two sets of passive soft-switching circuits can also achieve soft-switching features, their component counts and cost are increased significantly. To overcome the previously discussed drawbacks, an interleaved boost converter with a singlecapacitor turn-off snubber for battery charger applications is proposed, as shown in Figure 4. The proposed battery charger requires only a resonant capacitor $C_{S}$ which is associated with inductors $L_{1}$ and $L_{2}$ to reduce switching losses of active switches.

\section{Control Algorithm of the Proposed Charger}

In order to achieve an optimal power control of battery charger, an MPPT algorithm and a power management unit are needed. These control algorithms are described as follows.

2.1. Topology of Battery Charger. The proposed charger includes an interleaving boost converter and a controller, as shown in Figure 5. Moreover, the controller adopts microchip to implement MPPT of PV arrays and battery 


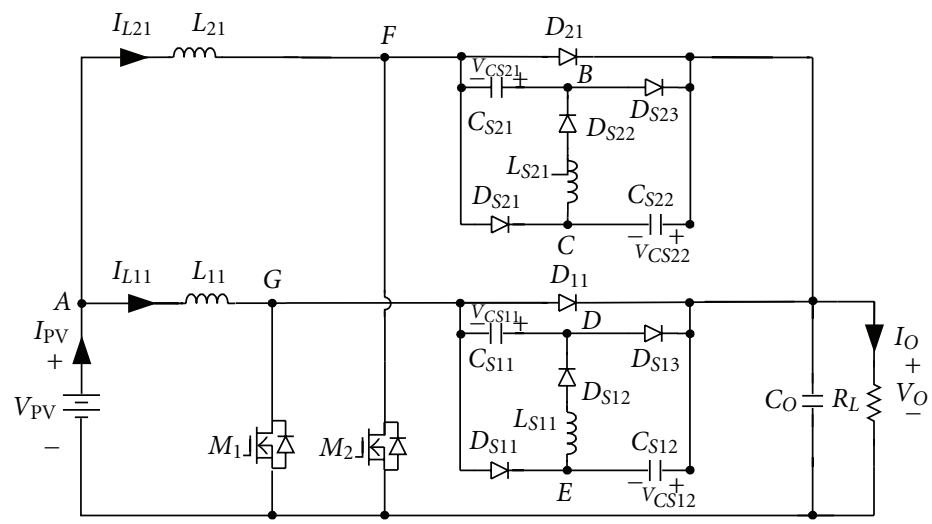

FIGURE 3: Topology of two sets of boost converters operated in an interleaving fashion.

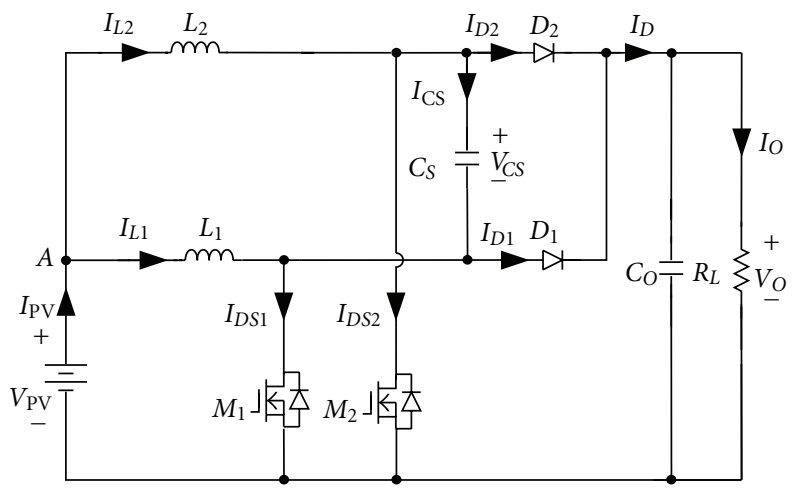

FIgURE 4: Topology of the proposed interleaving boost converter with a single-capacitor turn-off snubber for battery charger applications.

charging management. Therefore, the controller of the proposed battery charger can be divided into three units. They are MPPT operation, battery management, and power management units. The MPPT operation unit can implement the MPPT of PV arrays. The charging algorithm of battery charger is controlled with reflex charging method by battery management unit to reduce the charging time. In order to achieve the best energy utilization of the PV arrays, an MPPT with perturbation-and-observation method is integrated into an MPPT operation unit. Since the MPPT and charging algorithm must be associated to implement optimal control of battery charger, the power management unit is needed. To achieve optimal stability and safety for the proposed battery charger, the functions of under-voltage, over-current, and over-temperature protection circuits are required. All of the protection signals are also realized on a microchip.

2.2. MPPT Algorithm. Output characteristic variations of $\mathrm{PV}$ array depend on climatic conditions, such as temperature of PV arrays and insolation of sun. Its P-V curves at different insolation of the sun are shown in Figure 6. From Figure 6, it can be seen that each insolation level has a maximum power $P_{\max }$, where $P_{\max 1}$ is the maximum power at the largest insolation of sun while $P_{\max 3}$ is the one at the least insolation of sun. Three maximum power points $P_{\max 1} \sim P_{\max 3}$ can be connected by a straight line. Operational area on the right hand side of the straight line is defined as B area, while the one on the left hand side is defined as A area. Since output load connected in PV arrays increases, output voltage of PV arrays decreases. Therefore, when working point of PV arrays locates in A area, output load must decrease to make the working point to approach the maximum power point of PV arrays. On the other hand, when working point of PV arrays places on B area, output load must increase. Their operation conditions are shown in Figure 7. Figure 7(a) shows the working point located on A area, while Figure 7(b) illustrates the one located on $\mathrm{B}$ area. When working point locates on A area, the working point is changed from $A_{1}$ to maximum power point $P_{\max }$ at point $A_{6}$ through $A_{2}, A_{3}, A_{4}$, and $A_{5}$, as shown in Figure $7(\mathrm{a})$. When working point locates on $\mathrm{B}$ area, the working point is changed from $B_{1}$ to maximum power point $P_{\max }$ at point $B_{6}$ through $B_{2}, B_{3}, B_{4}$, and $B_{5}$, as shown in Figure $7(\mathrm{~b})$. According to different operational area to increase or decrease output load, working point of PV arrays can be shifted to MPP.

In order to extract maximum power of PV arrays, a simple perturbation-and-observation method is adopted. Its flow chart is shown in Figure 8. In the MPPT flow chart, $V_{n}$ and $I_{n}$ are, respectively, new voltage and current of PV arrays, $V_{P}$ and $P_{P}$ separately represent its old voltage and power value, and $P_{n}\left(=V_{n} I_{n}\right)$ is the new power value of $\mathrm{PV}$ 


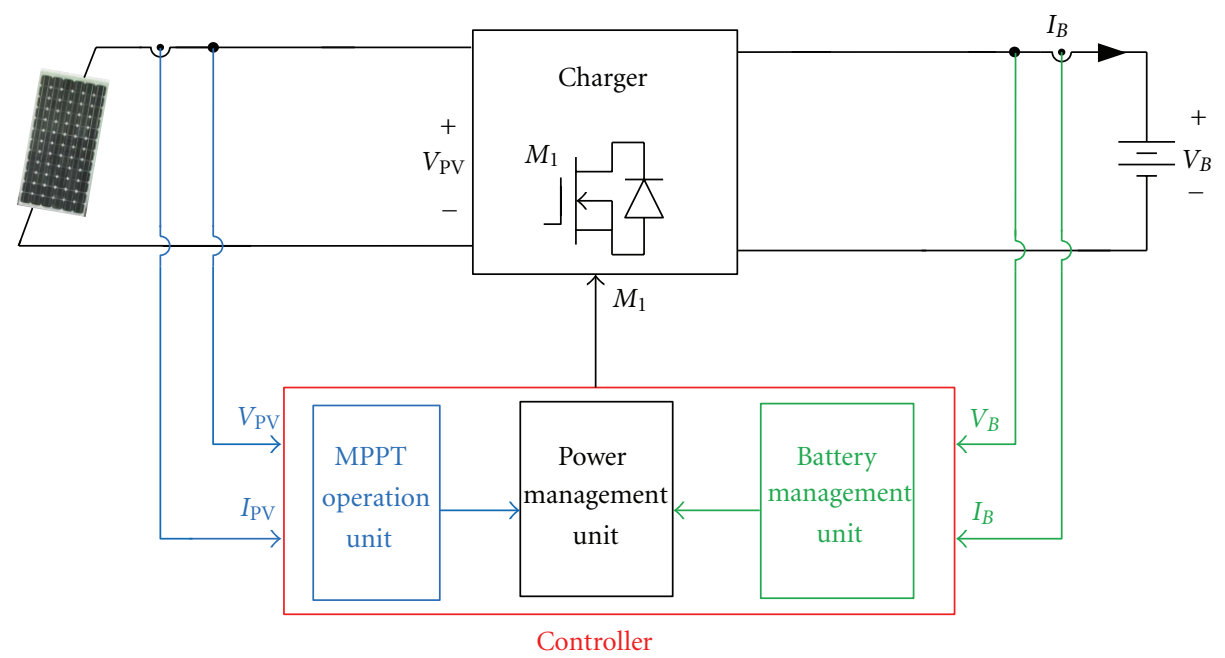

FIGURE 5: Block diagram of battery charger.

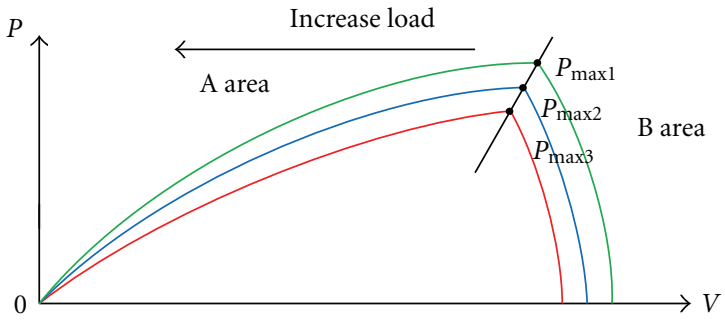

Figure 6: Plot of $P-V$ curves for PV arrays at different insolations of sun.

arrays. According to flow chart of MPPT using perturbationand observation-method, the first step is to read new voltage $V_{n}$ and current $I_{n}$ of PV arrays, and then to calculate new PV power $P_{n}$. The next step is to judge the relationship of $P_{n}$ and $P_{P}$. According to the relationship of $P_{n}$ and $P_{P}$ and procedures of MPPT flow chart, the procedure enters to judge the relationship of $V_{n}$ and $V_{P}$. When the relationship of $V_{n}$ and $V_{P}$ is decided, operational area of working point can be specified. According to control algorithm of MPPT, when the working point of PV arrays is located in A area, power system connected in PV arrays to supply load power must decrease output power to close the distance between working point and MPP of PV arrays. On the other hand, when the operating point is located in B area, $\mathrm{PV}$ power energy must be increased to approach maximum power point of PV arrays. Finally, the procedure of MPPT flow chart is returned to the first step to judge next maximum power point of PV arrays.

2.3. Power Management. The proposed charger is with a reflex charging method to reduce charging time, since the charging voltage and current of batteries must be limited for protecting battery life. The conceptual waveforms of charging current and voltage of battery charger with a reflex charging method are shown in Figure 9. Figure 9(a) shows reflex charging waveforms of battery charger under minimum battery voltage $V_{B(\min )}$, its $V_{B(\min )}$ is expressed as undercharge condition of battery voltage. Figure $9(\mathrm{~b})$ shows reflex charging waveforms of battery charger under maximum battery voltage $V_{B(\max )}$, its $V_{B(\max )}$ is expressed as overcharge condition of battery voltage. According to $V_{B(\min )}$ and $I_{B(\max )}$ or $V_{B(\max )}$ and $I_{B(\min )}$, the power limitation curve of battery charger can be obtained, as shown in Figure 9. When the maximum power $P_{\mathrm{PV}(\max )}$ of $\mathrm{PV}$ arrays is larger or less than $P_{\max 1}$, the power operation point of PV arrays is traced as shown in Figure 10. As mentioned previously, the charging and discharging power of the proposed charger will be limited by power curve to extend battery life.

\section{Derivation and Operational Principle of the Proposed Charger}

In order to describe the merits of the proposed battery charger, its topology derivation and operational principles are briefly described as follows.

3.1. Derivation of the Proposed Charger. To reduce switching losses, a lossless turn-off snubber is inserted in a basic boost converter as shown in Figure 2. When switch $M_{1}$ is turned on, capacitors $C_{S 1}$ and $C_{S 2}$ are charged through inductor $L_{s}$ and diode $D_{S 2}$ in a resonant manner. At the end of the resonant interval, capacitors $C_{S 1}$ and $C_{S 2}$ are charged to $V_{O}$ and are clamped at $V_{O}$ until switch $M_{1}$ is turned off. When switch $M_{1}$ is turned off, the charges stored 


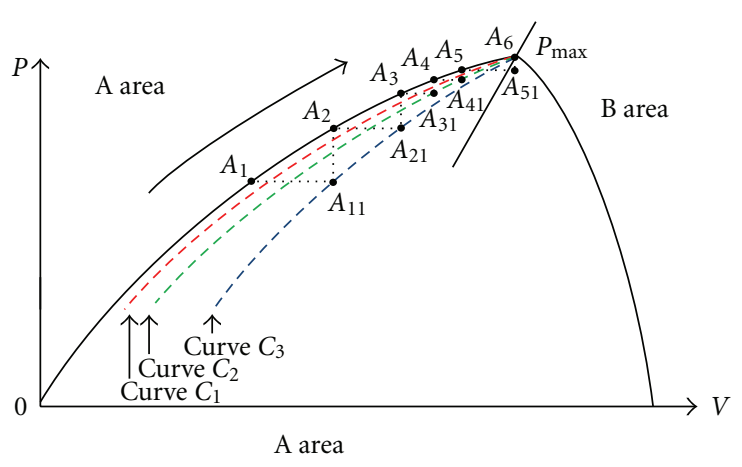

(a)

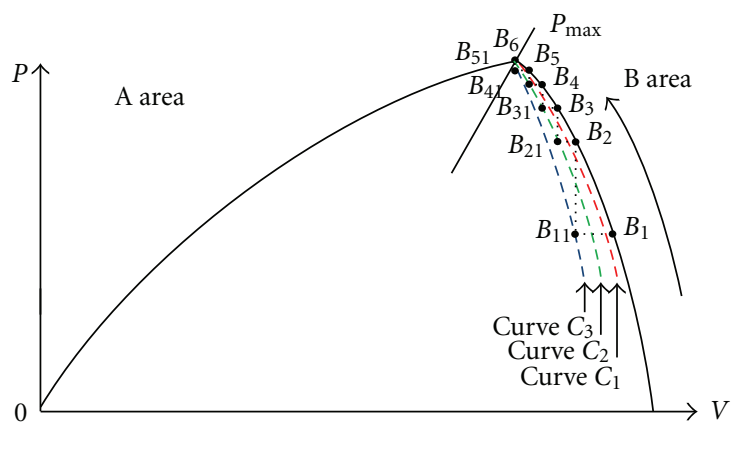

(b)

FIgURE 7: Illustration of PV arrays operated in (a) A area and (b) B area for MPPT.

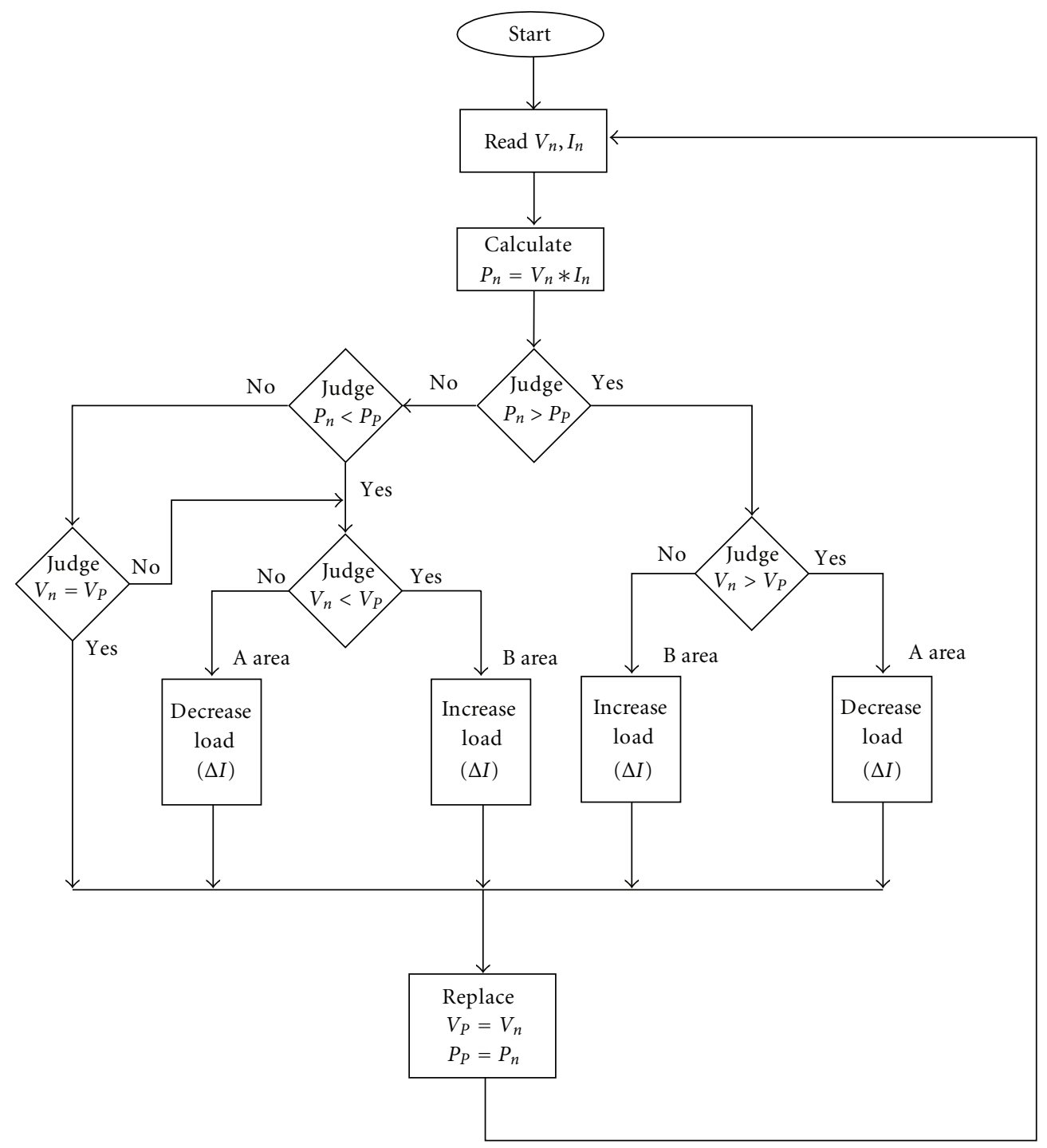

FIGURE 8: Flow chart of MPPT using perturbation-and-observation method for PV arrays system. 


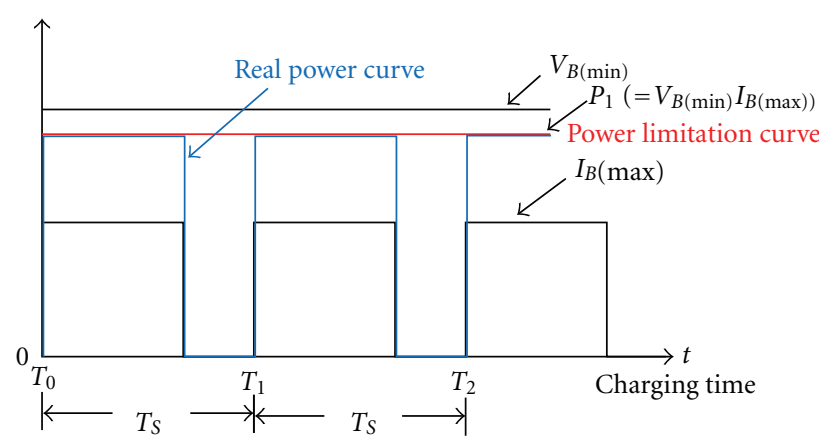

(a)

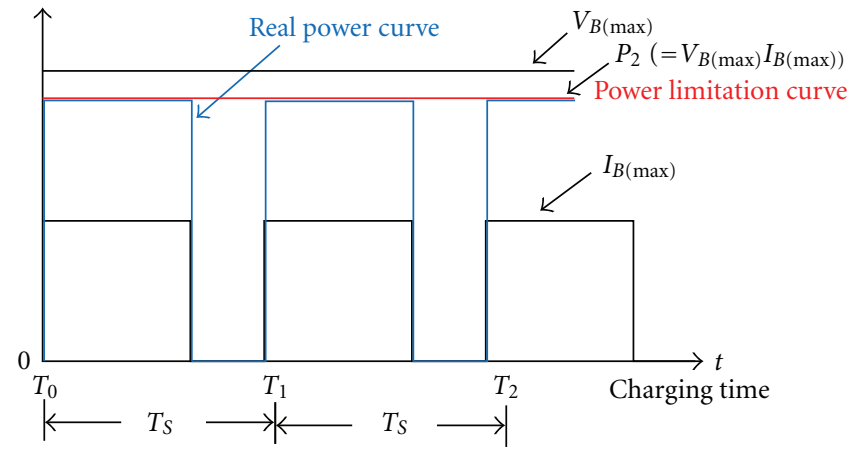

(b)

FIgURE 9: Conceptual waveforms of charging current, voltage and power for battery charger with reflex charging method (a) under the minimum battery voltage $V_{B(\min )}$ and (b) under the maximum battery voltage $V_{B(\max )}$.

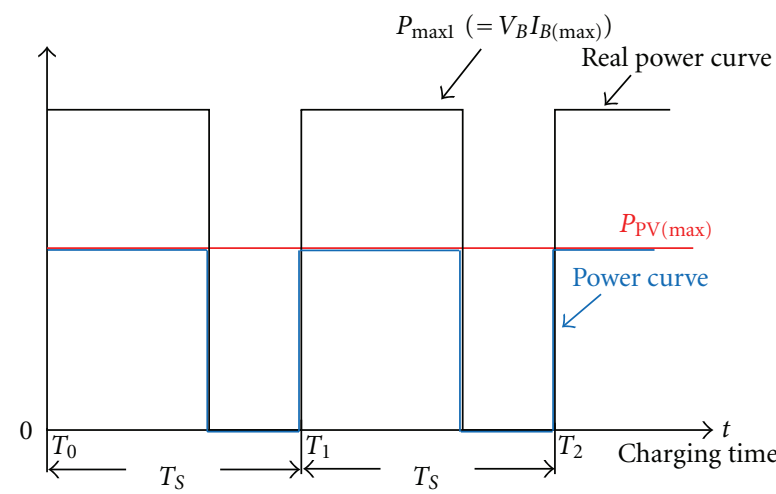

(a)

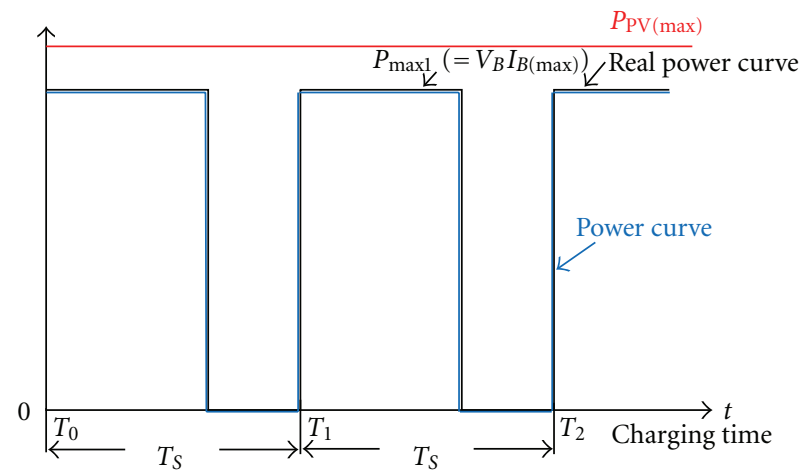

(b)

FIgURE 10: Conceptual power waveforms of PV arrays and battery charging power: (a) $P_{\mathrm{PV}(\max )} \leq P_{\max 1}$ and (b) $P_{\mathrm{PV}(\max )} \geq P_{\max 1}$.

in capacitors $C_{S 1}$ and $C_{S 2}$ are discharged to output load through diodes $D_{S 1}$ and $D_{S 3}$, respectively. Thus, switch $M_{1}$ is turned off with zero-voltage transition (ZVT). As mentioned previously, although it can achieve the soft-switching feature, its output current ripple is relatively large for high current and low output voltage applications. Therefore, to reduce output current ripple, an interleaving scheme is usually adopted. In the following, the proposed interleaving boost converter with a single-capacitor snubber is derived.

Two lossless turn-off snubbers are used in an interleaving boost converter to reduce switching losses, as shown in Figure 3. To simplify circuit of Figure 3, voltages of capacitors $C_{S 12}$ and $C_{S 22}$ are replaced with dc voltages $V_{C S 12}$ and $V_{C S 22}$, respectively. When voltages of capacitors $C_{S 12}$ and $C_{S 22}$ are replaced with dc voltages, the energies stored in capacitors $C_{S 12}$ and $C_{S 22}$ do not need to discharge their charges. Thus, diodes $D_{S 11}$ and $D_{S 21}$ can be removed, as shown in Figure 11(a). If voltage $V_{C S 12}$ or $V_{C S 22}$ is equal to $\left(V_{O}-V_{\mathrm{PV}}\right)$, nodes $\mathrm{A}, \mathrm{C}$, and $\mathrm{E}$ will have the same potential. Thus, they can be merged as node A, as shown in Figure 11(b). Based on the operational principle of an interleaving boost converters and the turn-off snubber, operational states of diode $D_{11}$ (or $D_{21}$ ) is the same as diode $D_{S 23}$ (or $D_{S 13}$ ) except that the operational duration of the turn-off snubber is operated within resonant mode. Since the duration of resonant mode is much shorter than a period of the proposed converters, nodes $\mathrm{F}$ and $\mathrm{D}$ (or G and $\mathrm{B}$ ) can be combined as the same node H (or I), as shown in Figure 11(c). It will not affect its original operational principle. Because inductor currents $I_{L 11}$ and $I_{L 21}$ are unidirectional in the derived converter, inductors $L_{11}$ and $L_{S 21}$ connected with diode $D_{S 22}$ in series can be combined and replaced by inductor $L_{1}$. Similarly, inductors $L_{21}$ and $L_{S 11}$ and diode $D_{S 12}$ can be also merged as inductor $L_{2}$, as shown in Figure 11(d). In Figure 11(c), since capacitors $C_{S 11}$ and $C_{S 21}$ and diodes $D_{11}$ and $D_{S 23}$ or $D_{21}$ and $D_{S 13}$ are, respectively, connected in parallel, they can be, respectively, incorporated as capacitor $C_{S}$ and diode $D_{1}$ or $D_{2}$. From Figure 11(d), it can be observed that the derived boost converter requires only a resonant capacitor $C_{S}$, which is associated with inductors $L_{1}$ and $L_{2}$ to function as a lossless turn-off snubber, reducing switching losses and component counts significantly. Therefore, Figure 11(d) is proposed for battery charger applications.

\subsection{Operational Principle of the Proposed Charger. In Figure} 4 , the proposed battery charger with a single-capacitor turnoff snubber can achieve a ZVT feature for active switches. Operational modes of the proposed charger are divided 


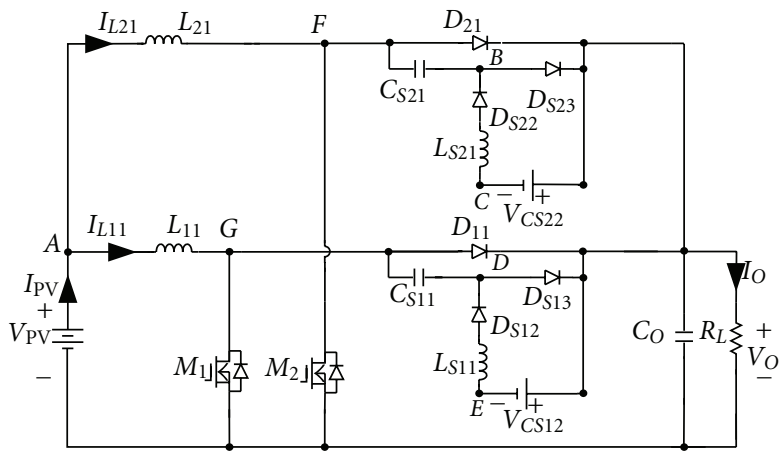

(a)

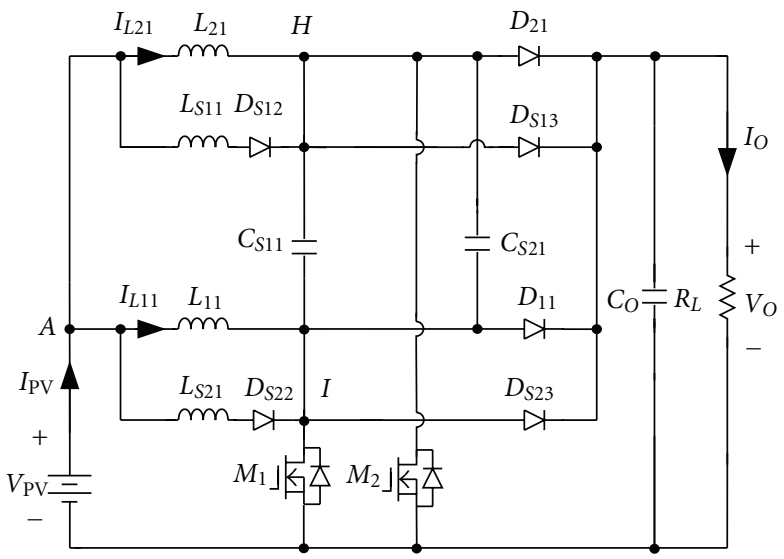

(c)

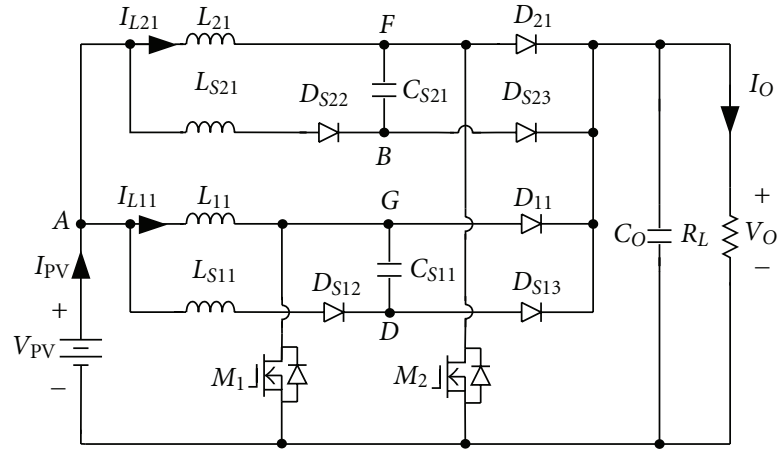

(b)

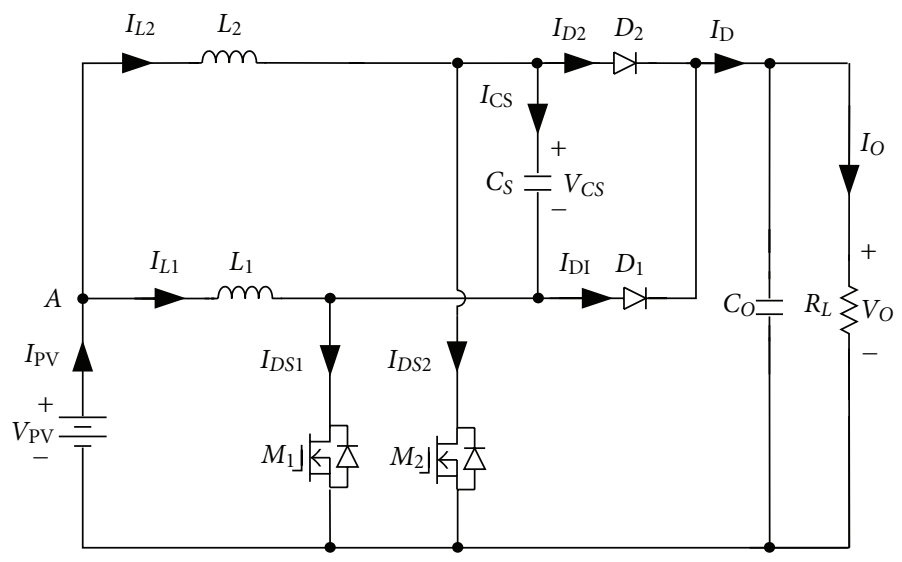

(d)

FIGURE 11: Derivation of the proposed battery charger with a single-capacitor turn-off snubber.

into ten modes, as illustrated in Figure 12, and their key waveforms are illustrated in Figure 13. In the following, each operational mode is described briefly.

Mode 1 (Figure 12(a); $t_{0} \leq t<t_{1}$ ). Before $t_{0}$, diode $D_{2}$ is in freewheeling, and inductor current $I_{L 2}$ is equal to diode current $I_{D 2}$. At $t=t_{0}$, switch $M_{1}$ is turned on. The equivalent circuit at this time interval is shown in Figure 12(a), from which it can be found that switch current $I_{D S 1}$ is equal to the sum of capacitor current $I_{C S}$ and inductor current $I_{L 1}$. Since the interval of $t_{0} \sim t_{1}$ is very short, inductor current $I_{L 1}$ is approximately equal to zero and capacitor voltage $V_{C S}$ is close to zero. Thus, switch current $I_{D S 1}$ is approximately equal to capacitor current $I_{C S}$. During this time interval, the current $I_{C S}$ is abruptly increased up to inductor current $I_{L 2}$, and $I_{D 2}$ is abruptly decreased down to zero.

Mode 2 (Figure 12(b); $t_{1} \leq t<t_{2}$ ). At time $t_{1}$, capacitor current $I_{C S}$ is equal to inductor current $I_{L 2}$, and diode $D_{2}$ is reversely biased. At this time interval, snubber capacitor $C_{S}$ resonates with inductor $L_{2}$, and switch current $I_{D S 1}$ is just equal to the sum of resonant inductor current $I_{L 2}\left(=I_{C S}\right)$ and inductor current $I_{L 1}$. At the same time, capacitor current
$I_{C S}$ reaches its maximum value which can be expressed as follows:

$$
I_{C S}=\frac{V_{i}}{Z_{O}}
$$

where $Z_{O}$ is the characteristic impedance of $L_{2}-C_{S}$ or $L_{2}-C_{S}$ network, which is equal to $\sqrt{L_{1} / C_{s}}$ or $\sqrt{L_{2} / C_{s}}$.

Mode 3 (Figure 12(c); $t_{2} \leq t<t_{3}$ ). When $t=t_{2}$, capacitor voltage $V_{C S}$ is equal to $V_{O}$, and diode $D_{2}$ starts freewheeling through inductor $L_{2}$. At the same time, switch $M_{1}$ is still in the on state. The switch current $I_{D S 1}$ is now equal to inductor current $I_{L 1}$ which increases linearly, while inductor current $I_{L 2}$ is decreased linearly.

Mode 4 (Figure 12(d); $t_{3} \leq t<t_{4}$ ). At time $t_{3}$, switch $M_{l}$ is turned off. Because inductor current $I_{L 1}$ must be continuous, capacitor $C_{S}$ starts to discharge for sustaining a continuous inductor current. Thus, switch $M_{1}$ can be turned off with ZVT.

Mode 5 (Figure $12(\mathrm{e}) ; t_{4} \leq t<t_{5}$ ). When time reaches $t_{4}$, the voltage $V_{C S}$ across capacitor $C_{S}$ is discharged toward zero, 


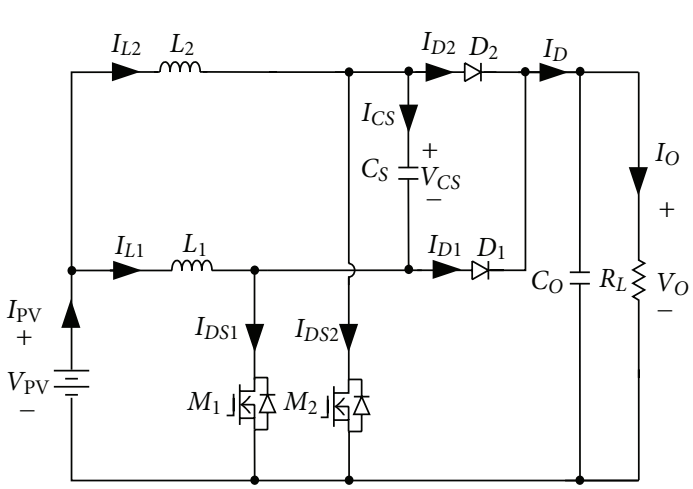

(a) Mode $1\left(t_{0} \leq t<t_{1}\right)$

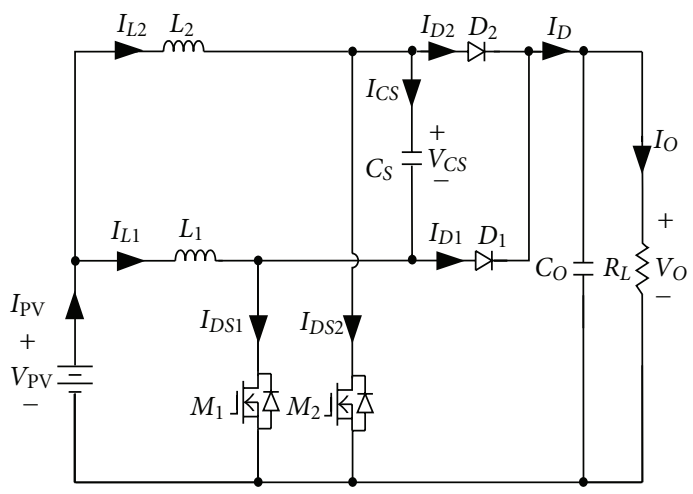

(b) Mode $2\left(t_{2} \leq t<t_{3}\right)$

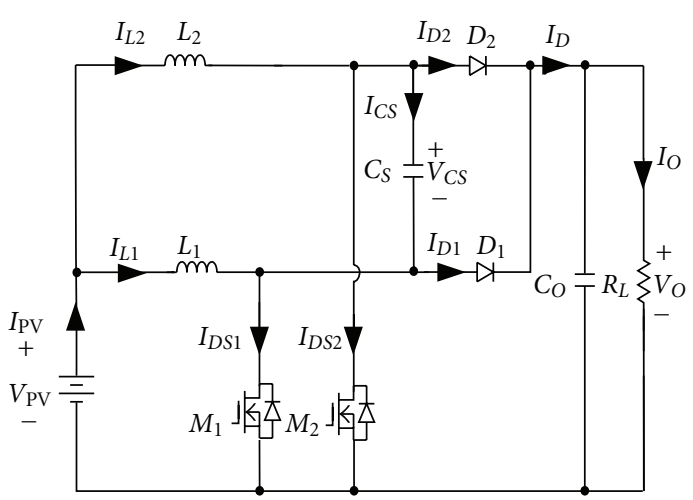

(c) Mode $3\left(t_{3} \leq t<t_{4}\right)$

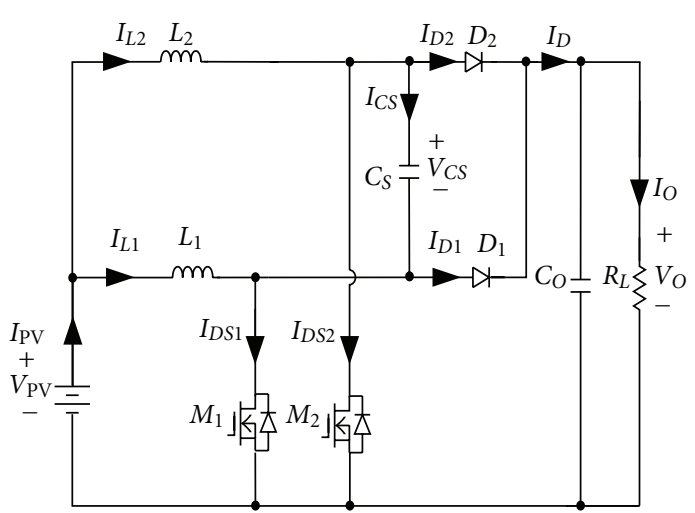

(d) Mode $4\left(t_{4} \leq t<t_{5}\right)$

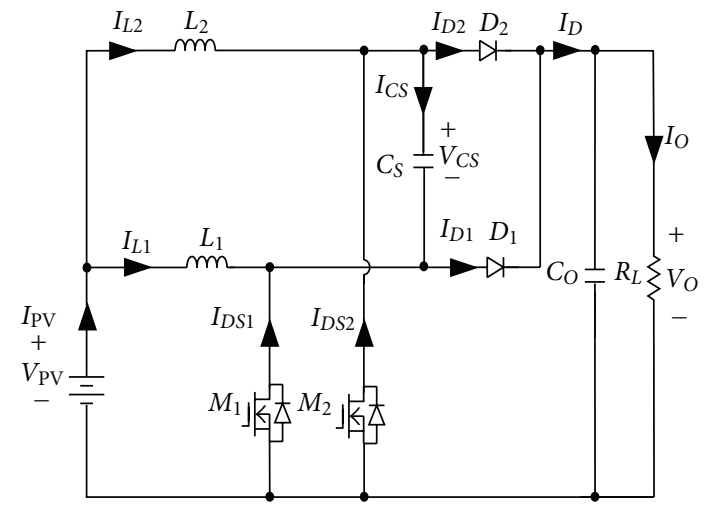

(e) Mode $5\left(t_{5} \leq t<t_{6}\right)$

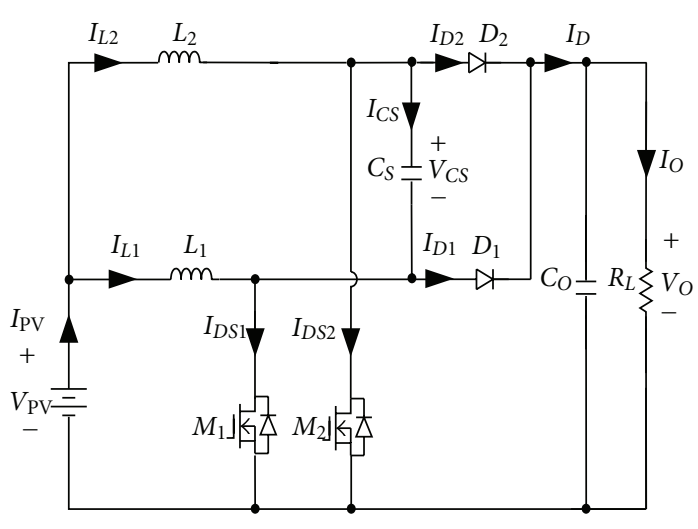

(f) Mode $6\left(t_{6} \leq t<t_{7}\right)$

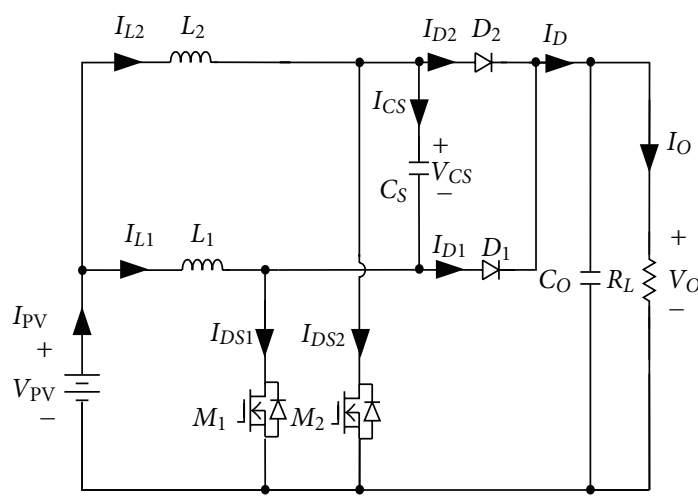

(g) Mode $7\left(t_{7} \leq t<t_{8}\right)$

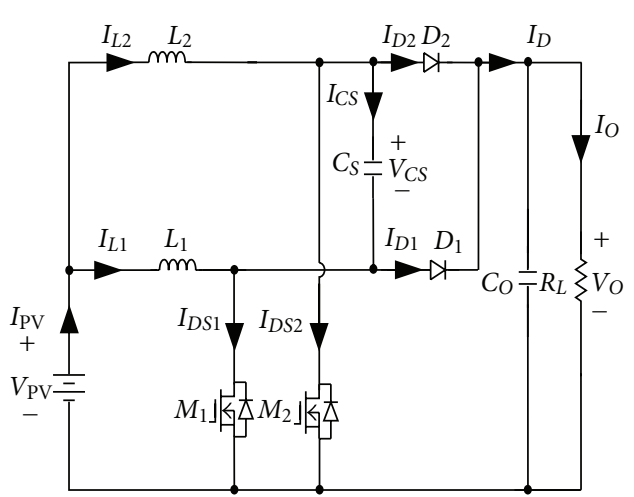

(h) Mode $8\left(t_{8} \leq t<t_{9}\right)$

Figure 12: Continued. 


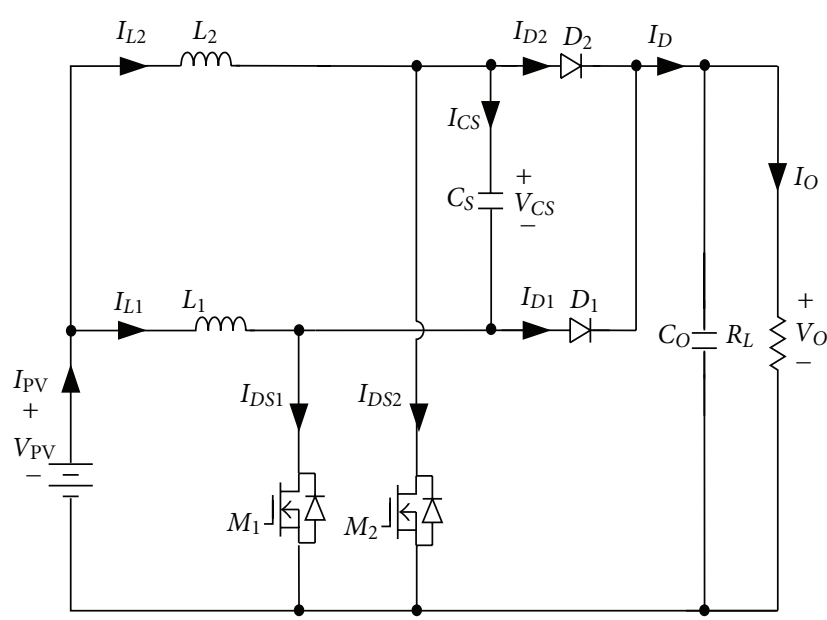

(i) Mode $9\left(t_{9} \leq t<t_{10}\right)$

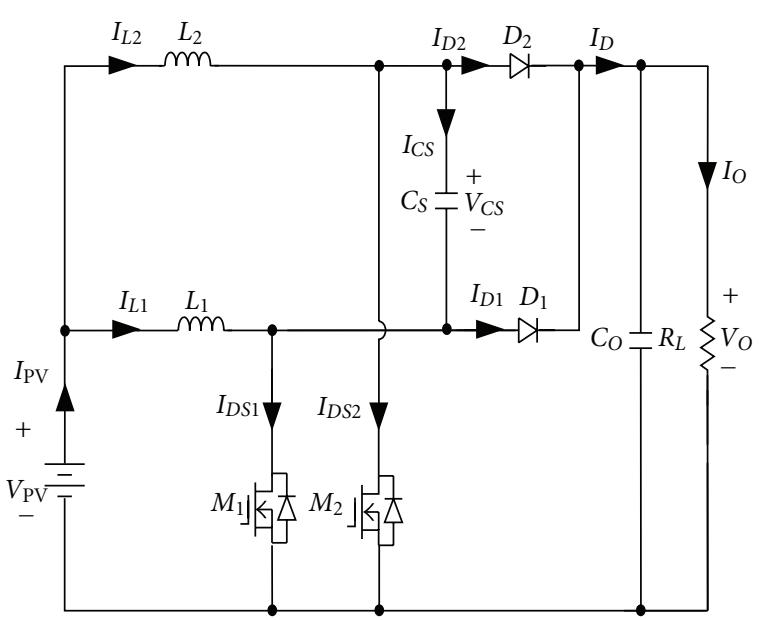

(j) Mode $10\left(t_{10} \leq t<t_{11}\right)$

Figure 12: Operational modes of the proposed battery charger over one switching cycle.

and diode $D_{1}$ starts freewheeling. During this time interval, diodes $D_{1}$ and $D_{2}$ are in freewheeling through inductors $L_{1}$ and $L_{2}$, respectively.

Mode 6 (Figure 12(f); $t_{5} \leq t<t_{6}$ ). At time $t_{5}$, diode $D_{1}$ is still in freewheeling, but diode $D_{2}$ stops freewheeling because inductor current $I_{L 2}$ drops to zero. In this moment, switch $M_{2}$ is turned on. Inductor current $I_{L 1}$ is equal to the sum of diode current $I_{D 1}$ and capacitor current $-I_{C S}$. Additionally, because the switch current $I_{D S 2}$ will flow through the lowimpedance path of capacitor $C_{S}$, diode current $I_{D 1}$ will be dominated by the switch current $I_{D S 2}$. That is, within this time duration, capacitor current $-I_{C S}$ is approximately equal to the switch current $I_{D S 2}$. Capacitor current $-I_{C S}$ is abruptly increased up to inductor current $I_{L 1}$, and $I_{D 1}$ is abruptly decreased down to zero.

Mode 7 (Figure $12(\mathrm{~g}) ; t_{6} \leq t<t_{7}$ ). At time $t_{6}$, diode $D_{1}$ is reversely biased, and resonant network formed by capacitor $C_{S}$ and inductor $L_{1}$ starts resonating. The switch current $I_{D S 2}$ is equal to the sum of inductor current $I_{L 1}\left(=-I_{C S}\right)$ and inductor current $I_{L 2}$, and capacitor $C_{S}$ is reversely charged.

Mode 8 (Figure 12(h); $t_{7} \leq t<t_{8}$ ). At $t=t_{7}$, the capacitor voltage $V_{C S}$ goes down to $-V_{O}$. The time interval lasts approximately a quarter of the resonant cycle. At the same time, capacitor current $-I_{C S}$ reaches its maximum value, which can be expressed by (1). During this mode, diode $D_{1}$ starts freewheeling, and inductor current $I_{L 2}$ is increased linearly.

Mode 9 (Figure 12(i); $t_{8} \leq t<t_{9}$ ). At time $t_{8}$, switch $M_{2}$ is turned off. Since the inductor current $I_{L 2}$ must be in smooth transition, capacitor voltage will drop to maintain a continuous inductor current. When $t=t_{9}$, capacitor voltage $V_{C S}$ drops to zero.

Mode 10 (Figure 12(j); $t_{9} \leq t<t_{10}$ ). During this time interval, diodes $D_{1}$ and $D_{2}$ are in freewheeling through inductors $L_{1}$ and $L_{2}$, and their currents $I_{D 1}$ and $I_{D 2}$ are decreased linearly. When switch $M_{l}$ is turned on again at the end of Mode 10, a new switching cycle will be recycled.

\section{Control and Design of the Proposed Charger}

In order to achieve optimal control of the proposed charger, the MPPT operation algorithm of PV arrays and reflex charging algorithm of battery must be considered. In the following, control and design of the proposed charger are described.

4.1. Control of the Proposed Charger. The proposed charger consists of an interleaving boost converter and controller. The controller adopts microchip of CY8C27443 made by Cypress Company. Block diagram of the proposed charger is shown in Figure 14. In Figure 14, the CY8C27443 microchip is divided into three units: MPPT, battery management, and power management units. In MPPT unit, the perturbationand-observation method is adopted to trace maximum power point of $\mathrm{PV}$ arrays. The maximum power $P_{P}$ of $\mathrm{PV}$ arrays can be decided. Moreover, battery management unit has four input signals $\left(V_{B}, V_{B(\max )}, I_{B}\right.$, and $\left.I_{B(\max )}\right)$ where $V_{B}$ is the battery voltage, $V_{B(\max )}$ is the set maximum battery voltage, $I_{B}$ is the battery charging current, and $I_{B(\max )}$ is the set maximum battery charging current. According to four input signals, $P_{B}\left(=V_{B} I_{B}\right)$ and $P_{B(\max )}\left(=V_{B} I_{B(\max )}\right)$ can be calculated. The $P_{B}$ represents the present charging power of battery, while $P_{B(\max )}$ is the set maximum charging power. In addition, when $V_{B}$ is equal to or greater than $V_{B(\max )}$, protection judgment makes output signal $S_{P}$ from low to high value. The $S_{P}$ is sent to PWM generator for shutdown PWM generator to avoid battery overcharge. In power management unit, a comparator is used to judge relationship of $P_{P}$ and $P_{B(\max )}$. When $P_{P}\left(=P_{\mathrm{PV}(\max )}\right)$ is greater than $P_{B(\max )}$, signal $S_{1}$ is high and switch selector is operated to set $P_{\text {set }}=P_{B(\max )}$. When $P_{P}$ is equal to or less than $P_{B(\max )}$, signal $S_{1}$ is low and switch selector is operated to set 


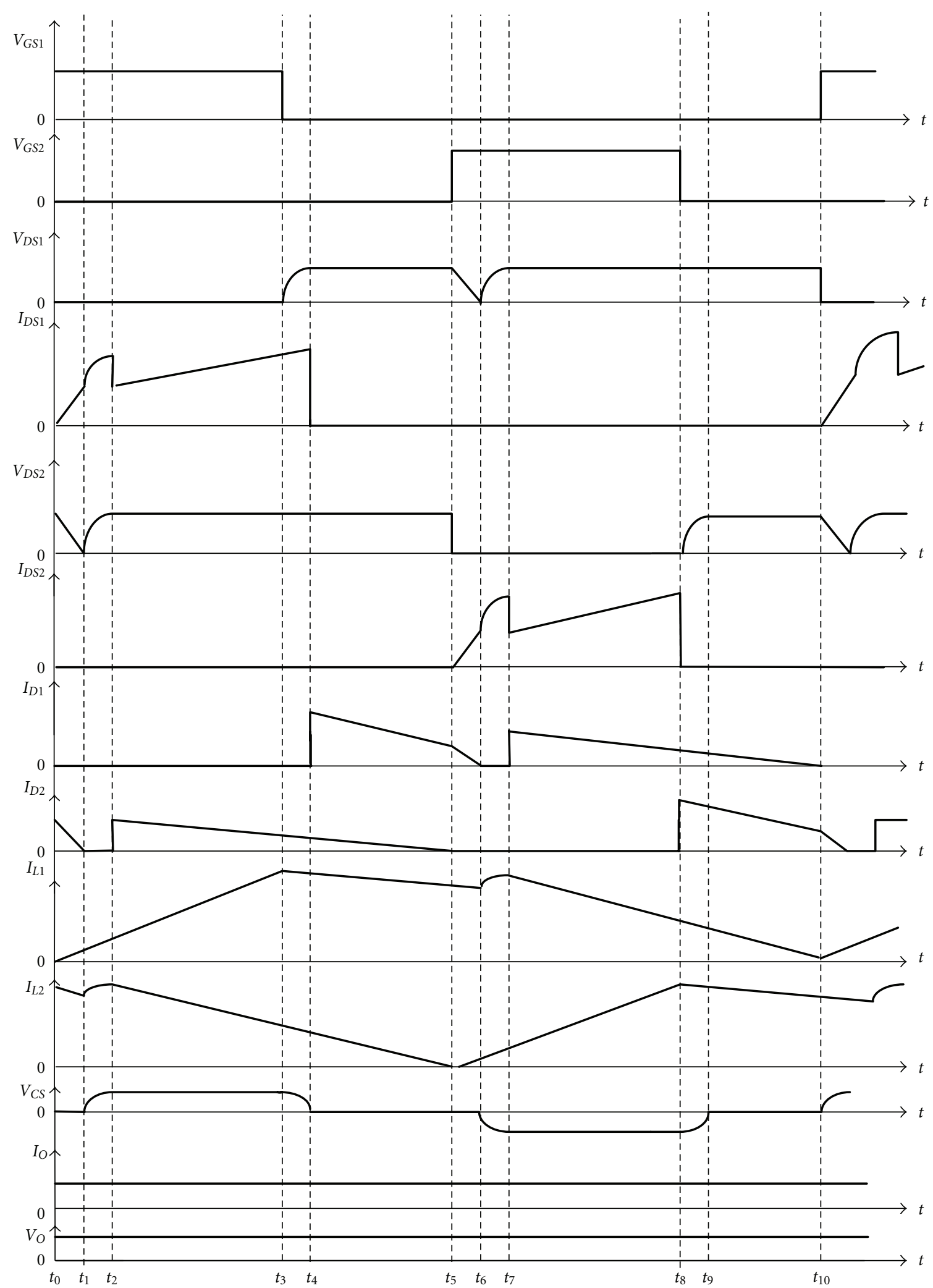

FIGURE 13: Key waveforms of the proposed battery charger operating over one switching cycle. 


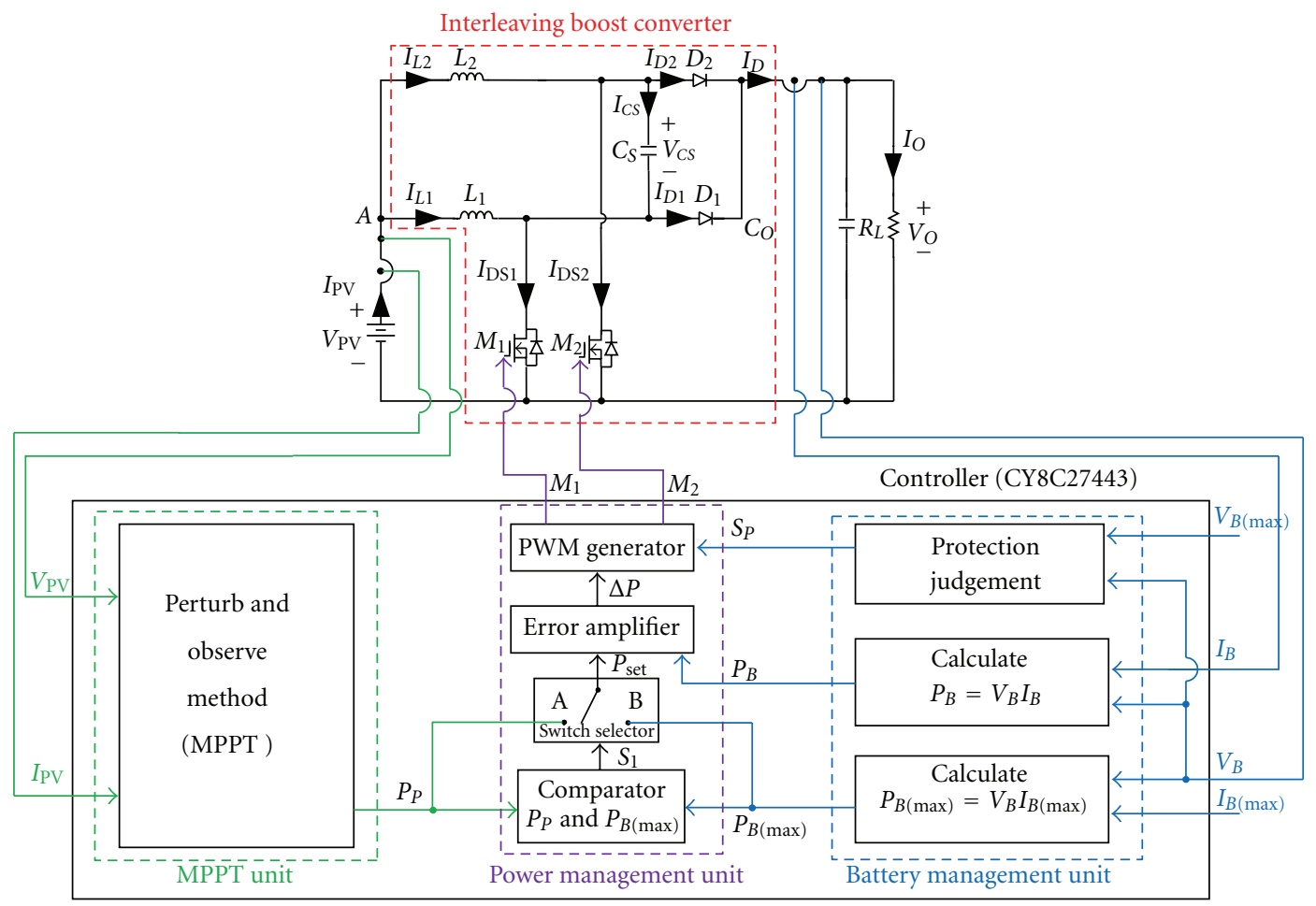

FIGURE 14: Block diagram of the proposed battery charger.

$P_{\text {set }}=P_{B}$. The $P_{\text {set }}$ and $P_{B}$ are sent to error amplifier to attain error value $\Delta P$. When PWM generator attains $\Delta P, \Delta P$ and triangle waves inside PWM generator attain PWM signals $M_{1}$ and $M_{2}$ via the comparator. The interleaving boost converter can change charging current $I_{B}$ according to PWM signals $M_{1}$ and $M_{2}$.

4.2. Design of the Proposed Charger. To realize the proposed soft-switching charger systematically, design of inductor $L_{1}$ or $L_{2}$ and the snubber $C_{S}$ are presented as follows.

4.2.1. Design of Inductor $L_{1}$ or $L_{2}$. Since the proposed charger is operated at the boundary of continuous conduction mode (CCM) and discontinuous conduction mode (DCM), the relationship between $V_{i}$ and $V_{O}$ can be attained with volt-second balance principle. Thus, transfer function $M$ (= $\left.V_{\mathrm{O}} / V_{\mathrm{PV}}\right)$ can be expressed as

$$
M=\frac{1}{1-D}
$$

where $D$ is duty ratio of the proposed charger. When duty ratio $D$ is determined by the relationship between $V_{\mathrm{PV}}$ and $V_{O}$, inductor $L_{1}$ or $L_{2}$ can also be expressed as

$$
L_{1}=L_{2}=\frac{D(1-D) V_{O}}{2 I_{O}} T_{S}
$$

where $T_{S}$ is the switching cycle of the proposed charger and $I_{O}$ is output current.
4.2.2. Design of Snubber Capacitor $C_{S}$. In the proposed charger, capacitor $C_{S}$ resonates with inductor $L_{1}$ or $L_{2}$ to smooth out switch voltage at turn-off transition. The energy stored in $C_{S}$ can be determined as

$$
W_{C S}=\frac{1}{2} C_{S} V_{O}^{2}
$$

To completely eliminate the switch turn-off loss, the energy stored in capacitor $C_{S}$ must be at least equal to the turn-off loss $W_{S \text { off }}$. According to switching loss calculation of switch, $W_{\text {Soff }}$ can be expressed by

$$
W_{\text {off }}=\frac{t_{\text {Soff }}}{2} V_{O} I_{\mathrm{DP}}
$$

where $t_{S \text { off }}$ is the falling time of switch at turn-off transition, $V_{O}$ represents output voltage and $I_{\mathrm{DP}}$ is switch current at turn-off transition of switch. Therefore, capacitor $C_{S}$ can be determined as

$$
C_{S} \geq \frac{I_{\mathrm{DP}}}{V_{O}} t_{S \text { off }}
$$

The peak current $I_{C S}$ of capacitor $C_{S}$ should be limited to being less than the peak values of $I_{D S 1}$ and $I_{D S 2}$, so it will not increase the current ratings of switches $M_{1}$ or $M_{2}$. To eliminate turn-off loss $W_{S \text { off }}$ completely at different operation conditions, the time $t_{S \text { off }}$ is approximately equal to $200 \mathrm{~ns}$ in practical design considerations. 


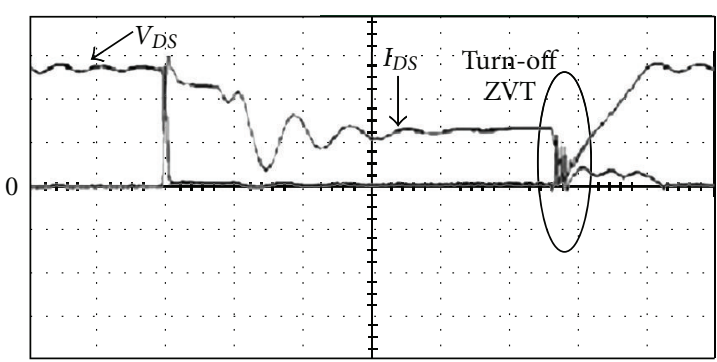

(a) $\left(V_{D S 1}: 50 \mathrm{~V} / \mathrm{div}, I_{D S 1}: 5 \mathrm{~A} / \mathrm{div}\right.$, time: $\left.1 \mu \mathrm{s} / \mathrm{div}\right)$

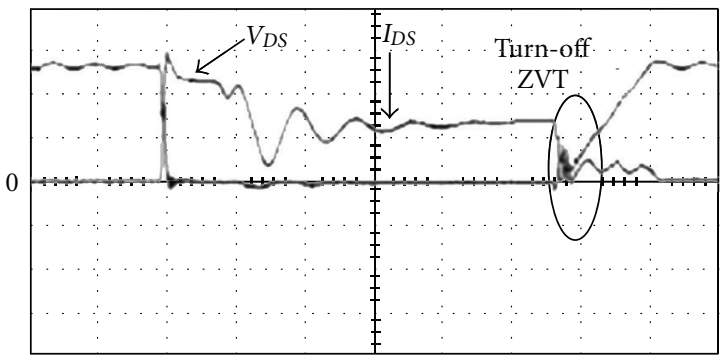

(b) $\left(V_{D S 1}: 50 \mathrm{~V} / \mathrm{div}, I_{D S 1}: 5 \mathrm{~A} / \mathrm{div}\right.$, time: $\left.1 \mu \mathrm{s} / \mathrm{div}\right)$

FIGURE 15: Measured voltage and current waveforms of (a) switch $M_{1}$, and (b) switch $M_{2}$ in the proposed converters.

\section{Measurements and Results}

To verify the analysis and discussion, a PV system used to charge $48 \mathrm{~V}$ battery with the following specifications was implemented:

(i) input voltage $V_{i}: 34 \sim 42 V_{\mathrm{dc}}$ (PV arrays),

(ii) output voltage $V_{O}: 44 \sim 54 V_{\mathrm{dc}}$ (4 sets of $12 \mathrm{~V}$ battery connected in series),

(iii) output maximum current $I_{O(\max )}: 10 \mathrm{~A}$,

(iv) output maximum power $P_{O(\max )}: 540 \mathrm{~W}$.

From (6), value of snubber capacitor $C_{S}$ can be calculated as $37 \mathrm{nF}$ where $I_{\mathrm{DP}}$ is $10 \mathrm{~A}$ and $V_{O}$ is $54 \mathrm{~V}$. In our design sample, a capacitor with $39 \mathrm{nF}$ is adopted. The components of power stage in the proposed boost converters are determined as follows:

(i) $M_{1}, M_{2}$ : IRFP250,

(ii) $D_{1}, D_{2}$ : MVUR1560,

(iii) $C_{O}: 470 \mu \mathrm{F}$,

(iv) $L_{1}, L_{2}: 30 \mu \mathrm{H}$,

(v) $C_{S}: 39 \mathrm{nF}$,

(vi) inductor core: EE-35.

The measured voltage and current waveforms of the active switches with the proposed single-capacitor snubber (as shown in Figure 4) and with two sets of turn-off snubbers (as shown in Figure 3) are shown in Figures 15 and 16, respectively. Although we can observe that each power switch is turned off with ZVT feature, there still exist significant differences. Compare with Figures 15 and 16, we can see

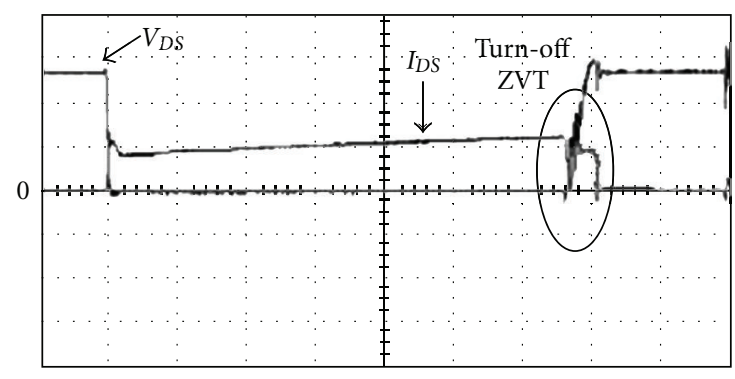

Figure 16: ( $V_{D S 1}: 50 \mathrm{~V} / \mathrm{div}, I_{D S 1}: 5 \mathrm{~A} / \mathrm{div}$, time: $\left.1 \mu \mathrm{s} / \mathrm{div}\right)$. Measured voltage and current waveforms of switch in the interleaved boost converter with two sets of turn-off snubbers.

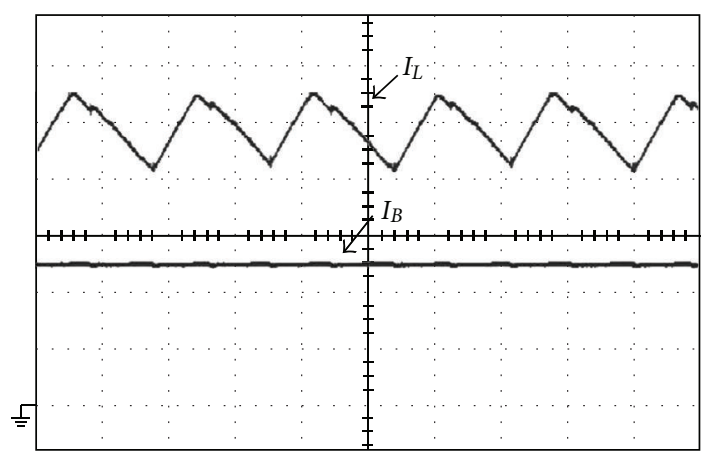

(a) $\left(I_{L}: 1 \mathrm{~A} / \mathrm{div}, I_{B}: 5 \mathrm{~A} /\right.$ div, time: $\left.10 \mu \mathrm{s} / \mathrm{div}\right)$

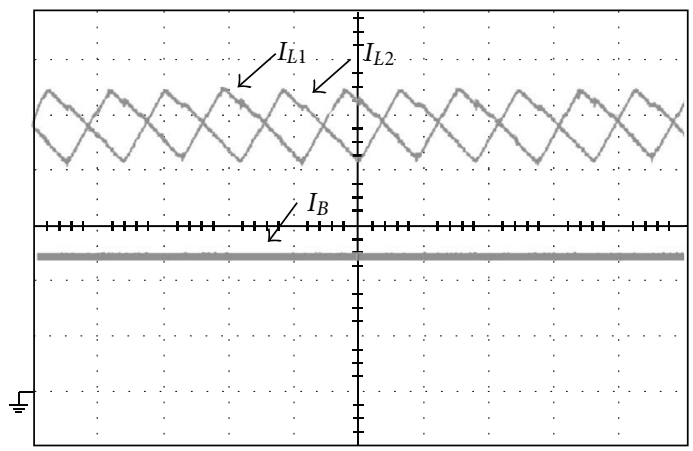

(b) $\left(I_{L 1}, I_{L 2}: 1 \mathrm{~A} / \mathrm{div}, I_{B}: 5 \mathrm{~A} / \mathrm{div}\right.$, time: $\left.10 \mu \mathrm{s} / \mathrm{div}\right)$

FIGURE 17: Measured waveforms of inductor current $I_{L}$ and charging current $I_{B}$ of (a) single boost converter and (b) the proposed interleaving boost converter.

that the rise voltage curves of Figure 15 are smoother than those of Figure 16. The reason of this is that interleaving boost converter with two sets of turn-off snubbers, causes an abrupt energy on active switches and results in more switching losses. Figure 17(a) shows measured inductor current and charging current of the single boost converter with a turn-off snubber, and Figure 17(b) shows measured inductor current and charging current of the proposed interleaved boost converter with a single-capacitor turn-off snubber. From Figure 17, it can be seen that the proposed converter with a single-capacitor turn-off snubber has a lower ripple charging current $I_{B}$.

To make a fair comparison, the hardware components of the proposed charger and hard-switching boost charger 


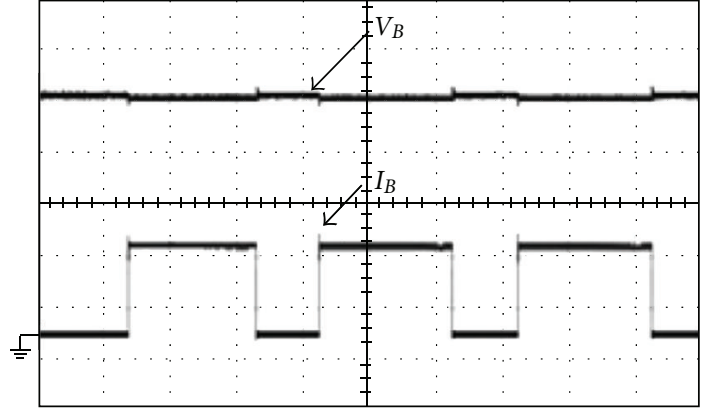

(a) $\left(V_{B}: 10 \mathrm{~V} / \mathrm{div}, I_{B}: 3 \mathrm{~A} / \mathrm{div}\right)$

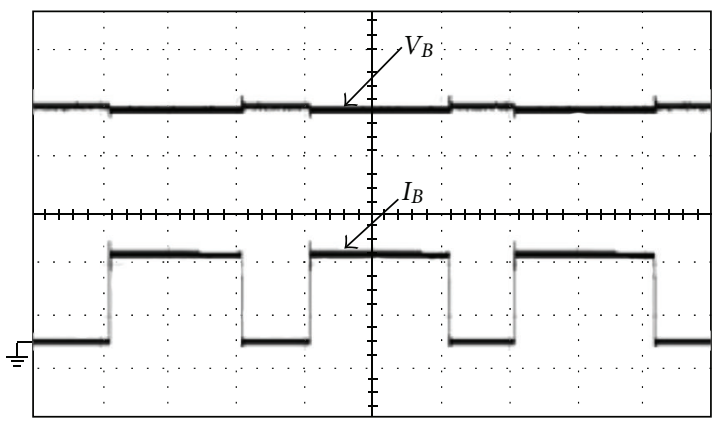

(b) $\left(V_{B}: 10 \mathrm{~V} / \mathrm{div}, I_{B}: 3 \mathrm{~A} / \operatorname{div}\right)$

FIGURE 18: Battery voltage $V_{B}$ and charging current $I_{B}$ under stepload changes between $20 \%$ and $100 \%$ of full load of the discussed interleaving boost converters with (a) hard switching (b) a singlecapacitor turn-off snubber.

are kept as the same as possible. Figure 18 shows the plots of output voltage and current waveforms of the two kinds of chargers under step-load changes between $20 \%$ and $100 \%$ with, respectively, rate of $1 \mathrm{kHz}$ and a duty ratio of $50 \%$. From Figure 18, it can be observed that although the proposed charger uses less component counts, it yields almost the same dynamic performance as those with complicated configurations. The comparisons between the efficiencies of the proposed charger and their counterparts are illustrated in Figure 19. It can be observed that the proposed charger cannot always yield higher efficiencies than the others under various operating conditions. It has a trend that, at higher output load, the proposed charger and the ones with two turn-off snubbers can yield higher efficiency, while at lower ones, the discussed charger with two sets of turn-off snubbers yields lower efficiency than the others. The reasons behind this are that at a fixed power level, a higher output load level will result in higher switch currents and the turn-off losses $W_{S \text { off }}$ will be much higher than the sum of the extra conduction loss $W_{E S}$ and switching loss $W_{S \text { on }}$. Figure 20 shows the measured waveforms of battery voltage $V_{B}$ and charging current $I_{B}$ with pulse current charging method under repetitive rate of $1 \mathrm{~s}$ and duty ratio of $500 \mathrm{~ms}$, as shown in Figure 14. Figure 20(a) shows those waveforms under $P_{\mathrm{PV}(\max )}=50 \mathrm{~W}$, while Figure 20(b) illustrates those waveforms $P_{\mathrm{PV}(\max )}=100 \mathrm{~W}$. From Figure 20, it can be seen that maximum pulse charging current $I_{O(\max )}$, respectively, is limited $1 \mathrm{~A}$ (about $0.15 \mathrm{C}$ ) and

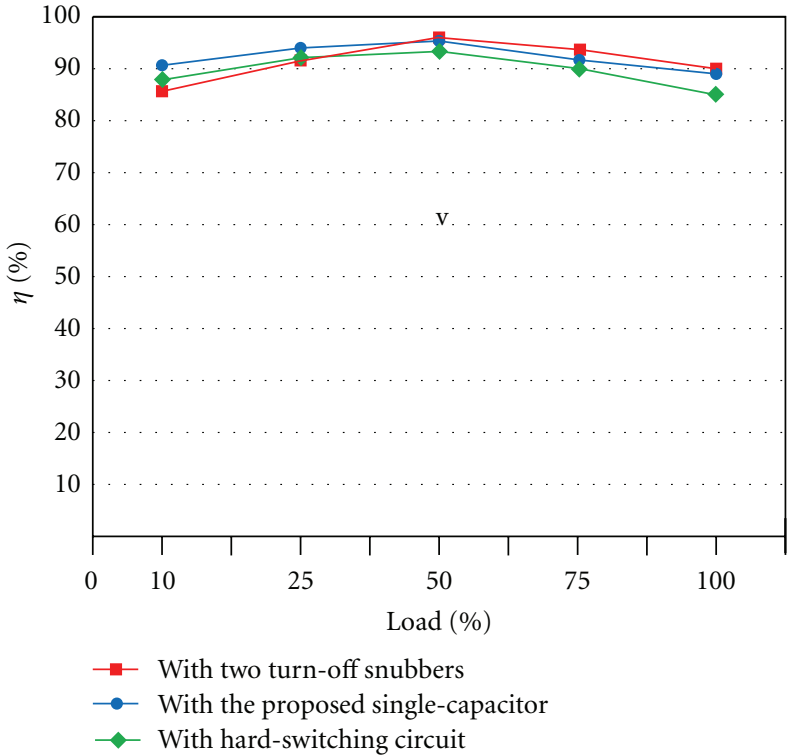

FIgURE 19: Comparison among efficiencies of the discussed interleaving boost converter with a single-capacitor turn-off snubber, hard switching, and two sets of turn-off snubbers from light load to heavy load.

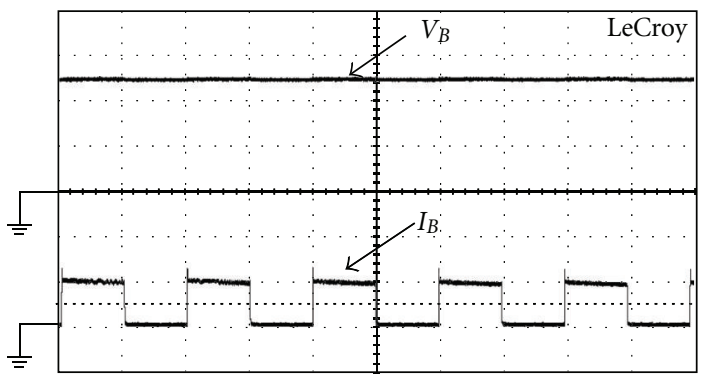

(a) $\left(V_{B}: 5 \mathrm{~V} / \mathrm{div}, I_{B}: 1 \mathrm{~A} / \mathrm{div}\right.$, time: $\left.500 \mathrm{~ms} / \mathrm{div}\right)$

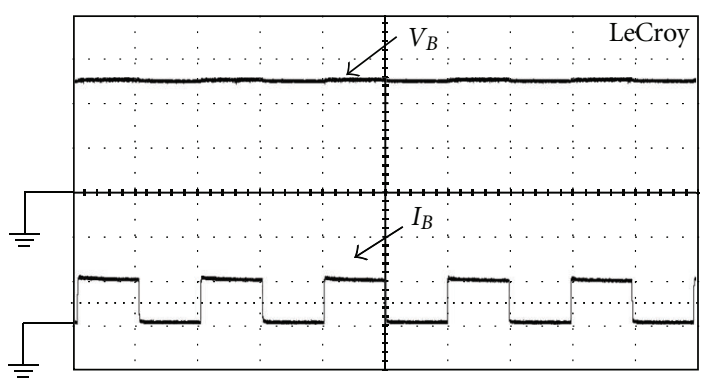

(b) $\left(V_{B}: 5 \mathrm{~V} / \mathrm{div}, I_{B}: 2 \mathrm{~A} / \mathrm{div}\right.$, time: $\left.500 \mathrm{~ms} / \mathrm{div}\right)$

Figure 20: Measured waveforms of battery voltage $V_{B}$ and charging current $I_{B}$ with pulse current charging method: (a) $I_{B(\max )}=$ $1 \mathrm{~A}$ and $(\mathrm{b}) I_{B(\max )}=2 \mathrm{~A}$.

$2 \mathrm{~A}$ (about $0.3 \mathrm{C}$ ), where battery adopts lead-acid battery and capacity of each battery is $12 \mathrm{~V} / 7 \mathrm{Ah}$ and total battery voltage is $50 \mathrm{~V}$. Measured waveforms of voltage $V_{\mathrm{PV}}$, current $I_{\mathrm{PV}}$ and power $P_{\mathrm{PV}}$ of $\mathrm{PV}$ arrays with perturbation-and-observation method are used to implement MPPT. Figure 21(a) shows those waveforms under maximum power point $P_{\mathrm{PV}(\max )}$ at $100 \mathrm{~W}$, while Figure 21(b) depicts those waveforms under 


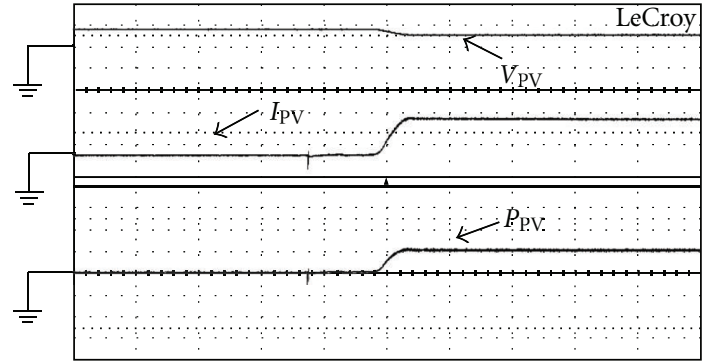

(a) $\left(V_{\mathrm{PV}}: 50 \mathrm{~V} / \mathrm{div}, I_{\mathrm{PV}}: 2 \mathrm{~A} / \mathrm{div}, P_{\mathrm{PV}}: 100 \mathrm{~W}\right.$, time: $\left.100 \mathrm{~ms} / \mathrm{div}\right)$

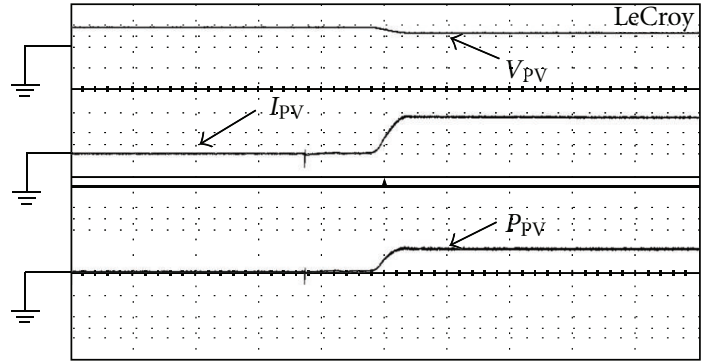

(b) $\left(V_{\mathrm{PV}}: 50 \mathrm{~V} / \mathrm{div}, I_{\mathrm{PV}}: 2 \mathrm{~A} / \mathrm{div}, P_{\mathrm{PV}}: 100 \mathrm{~W}\right.$, time: $\left.100 \mathrm{~ms} / \mathrm{div}\right)$

FIgURe 21: Measured waveforms of voltage $V_{\mathrm{PV}}$, current $I_{\mathrm{PV}}$ and Power $P_{\mathrm{VP}}$ of PV arrays with perturbation- and-observation method to implement MPPT: (a) $P_{\mathrm{PV}(\max )}=100 \mathrm{~W}$, and (b) $P_{\mathrm{PV}(\max )}=200 \mathrm{~W}$.

$P_{\mathrm{PV}(\max )}$ at $200 \mathrm{~W}$. From Figure 21, it can be found that tracking time of PV arrays from zero to the maximum power point is about $40 \mathrm{~ms}$.

\section{Conclusions}

In this paper, an interleaving boost converter with a passive snubber for battery charger applications is proposed. The proposed charger with a single-capacitor snubber to reduce voltage stresses of active switches at turn-off transition. Therefore, the conversion efficiency of the proposed charger can be increased significantly. In order to draw maximum power from the PV energy, a simple perturbation-andobservation method is incorporated to realize maximum power conversion. To verify the merits of the proposed charger, the operational principle, steady-state analysis, and design considerations have been described in detail. Additionally, from the experimental efficiency of the proposed charger, it has been shown that the proposed charger can yield higher efficiency at heavy load condition. An experimental prototype for a battery charger application $(540 \mathrm{~W}$, $54 V_{\mathrm{dc}} / 10 \mathrm{~A}$ ) has been built and evaluated, achieving the efficiency of $88 \%$ under full load condition. Therefore, the proposed interleaving boost converter is relatively suitable for battery charger applications.

\section{References}

[1] S. L. Brunton, C. W. Rowley, S. R. Kulkarni, and C. Clarkson, "Maximum power point tracking for photovoltaic optimization using ripple-based extremum seeking control," IEEE Transactions on Power Electronics, vol. 25, no. 10, pp. 25312540, 2010.

[2] V. Agarwal, R. K. Aggarwal, P. Patidar, and C. Patki, "A novel scheme for rapid tracking of maximum power point in wind energy generation systems," IEEE Transactions on Energy Conversion, vol. 25, no. 1, pp. 228-236, 2010.

[3] A. M. Subiyanto and S. Hussain, "Hopfield neural network optimized fuzzy logic controller for mximum power point tracking in a photovoltaic system," International Journal of Photoenergy, vol. 2012, Article ID 798361, 13 pages, 2012.

[4] M. Taherbaneh, A. H. Rezaie, H. Ghafoorifard, K. Rahimi, and M. B. Menhaj, "Maximizing output power of a solar panel via combination of sun tracking and maximum power point tracking by fuzzy controllers," International Journal of Photoenergy, vol. 2010, Article ID 312580, 13 pages, 2010.

[5] X. Weidong and W. G. Dunford, "A modified adaptive hill climbing MPPT method for photovoltaic power systems," in Proceedings of the IEEE 35th Annual Power Electronics Specialists Conference (PESC '04), vol. 3, pp. 1957-1963, June 2004.

[6] K. Kobayashi, H. Matsuo, and Y. Sekine, "An excellent operating point tracker of the solar-cell power supply system," IEEE Transactions on Industrial Electronics, vol. 53, no. 2, pp. 495499, 2006.

[7] S. Jain and V. Agarwal, "A new algorithm for rapid tracking of approximate maximum power point in photovoltaic systems," IEEE Power Electronics Letters, vol. 2, no. 1, pp. 16-19, 2004.

[8] H. S. H. Chung, K. K. Tse, S. Y. R. Hui, C. M. Mok, and M. T. Ho, "A novel maximum power point tracking technique for solar panels using a SEPIC or Cuk converter," IEEE Transactions on Power Electronics, vol. 18, no. 3, pp. 717-724, 2003.

[9] B. M. T. Ho and H. S. H. Chung, "An integrated inverter with maximum power tracking for grid-connected PV systems," APEC, vol. 3, pp. 953-962, 2004.

[10] D. Casadei, G. Grandi, and C. Rossi, "Single-phase single-stage photovoltaic generation system based on a ripple correlation control maximum power point tracking," IEEE Transactions on Energy Conversion, vol. 21, no. 2, pp. 562-568, 2006.

[11] A. A.-H. Hussein and I. Batarseh, "A review of charging algorithms for nickel and lithium battery chargers," IEEE Transactions on Vehicular Technology, vol. 60, no. 3, pp. 830838, 2011.

[12] F. Savoye, P. Venet, M. Millet, and J. Groot, "Impact of periodic current pulses on Li-Ion battery performance," IEEE Transactions on Industrial Electronics, vol. 59, no. 9, pp. 3481-3488, 2012.

[13] L. R. Chen, "Design of duty-varied voltage pulse charger for improving Li-ion battery-charging response," IEEE Transactions on Industrial Electronics, vol. 56, no. 2, pp. 480-487, 2009.

[14] Y. C. Chuang and Y. L. Ke, "High efficiency battery charger with a buck zero-current-switching pulse-width-modulated converter," Interactive Electronic Technical Specification, vol. 1, pp. 433-444, 2008.

[15] L. R. Chen, C. M. Young, N. Y. Chu, and C. S. Liu, "Phaselocked bidirectional converter with pulse charge function for 42-V/14-V dual-voltage PowerNet," IEEE Transactions on Industrial Electronics, vol. 58, no. 5, pp. 2045-2048, 2011.

[16] J. Yun, H.-J. Choe, Y.-H. Hwang, Y.-K. Park, and B. Kang, "Improvement of power-conversion efficiency of a DC-DC 
boost converter using a passive snubber circuit," IEEE Transactions on Industrial Electronics, vol. 59, no. 4, pp. 1808-1814, 2012.

[17] C. A. Gallo, F. L. Tofoli, and J. A. C. Pinto, "A passive lossless snubber applied to the ACDC interleaved boost converter," IEEE Transactions on Power Electronics, vol. 25, no. 3, pp. 775$785,2010$.

[18] C. Munoz, "Study of a new passive lossless turn-off snubber," CIEP, pp. 147-152, 1998.

[19] B. R. Lin and H. Y. Shih, "ZVS converter with parallel connection in primary side and series connection in secondary side," IEEE Transactions on Industrial Electronics, vol. 58, no. 4, pp. 1251-1258, 2011.

[20] T.-F. Wu, Y.-D. Chang, C.-H. Chang, and J.-G. Yang, "Softswitching boost converter with a flyback snubber for high power applications," IEEE Transactions on Power Electronics, vol. 27, no. 3, pp. 1108-1119, 2012.

[21] Y. K. Luo, Y. P. Su, Y. P. Huang, Y. H. Lee, K. H. Chen, and W. C. $\mathrm{Hsu}$, "Time-multiplexing current balance interleaved currentmode boost DC-DC converter for alleviating the effects of right-half-plane zero," IEEE Transactions on Power Electronics, vol. 27, no. 9, pp. 4098-4112, 2012. 


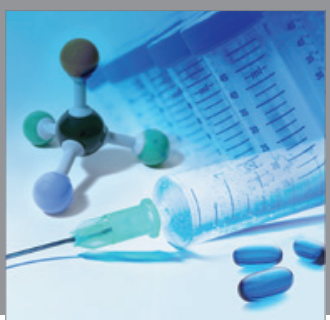

International Journal of

Medicinal Chemistry

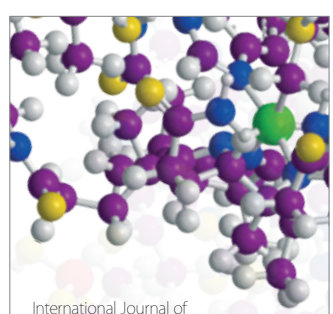

Carbohydrate Chemistry

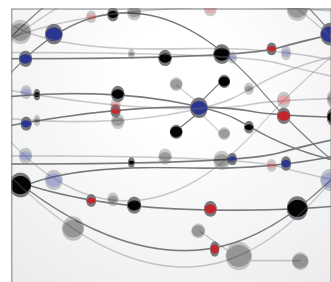

The Scientific World Journal
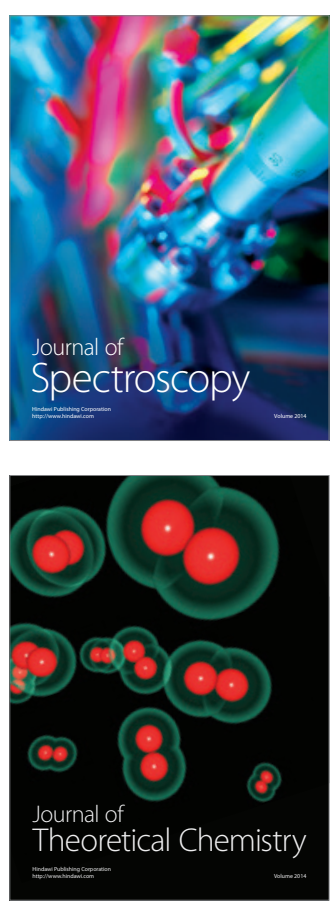
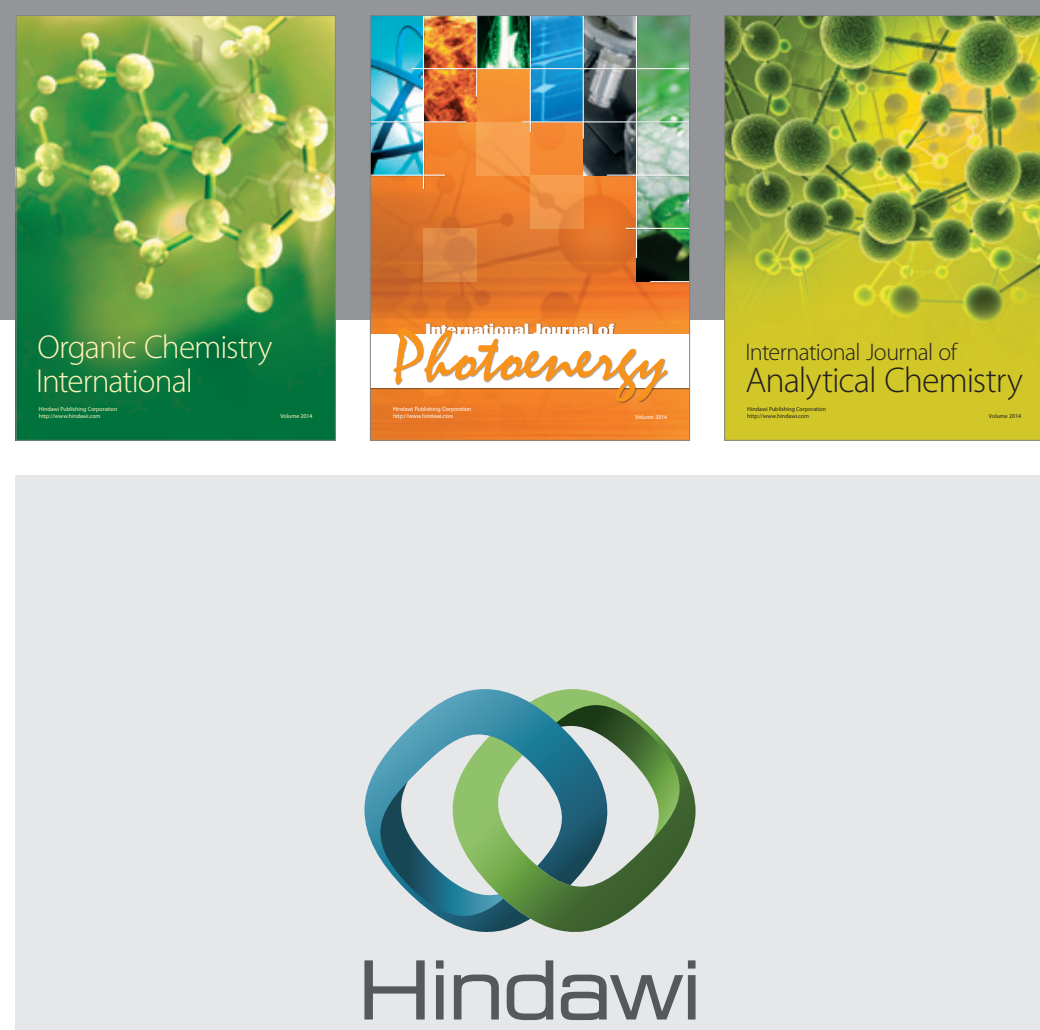

Submit your manuscripts at

http://www.hindawi.com
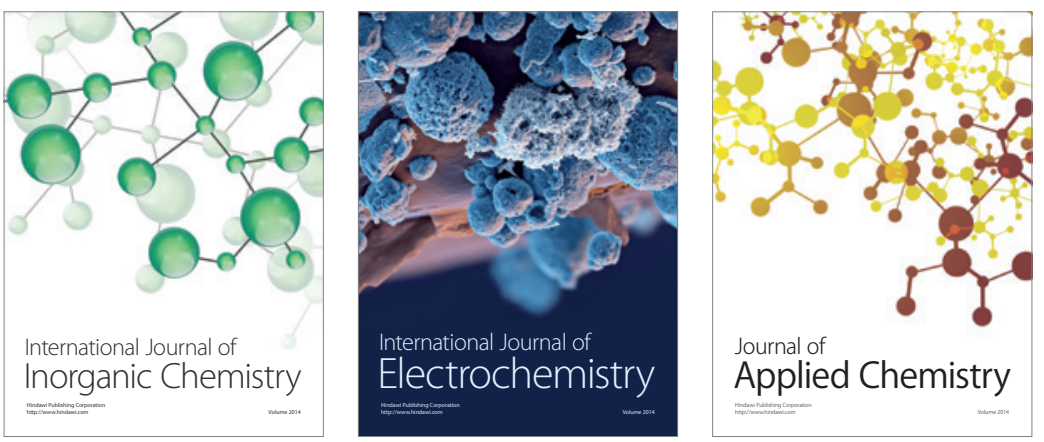

Journal of

Applied Chemistry
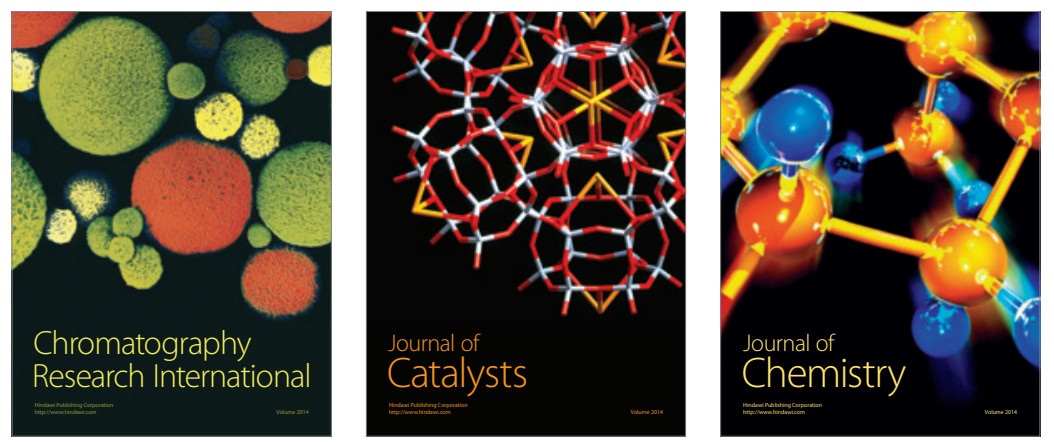
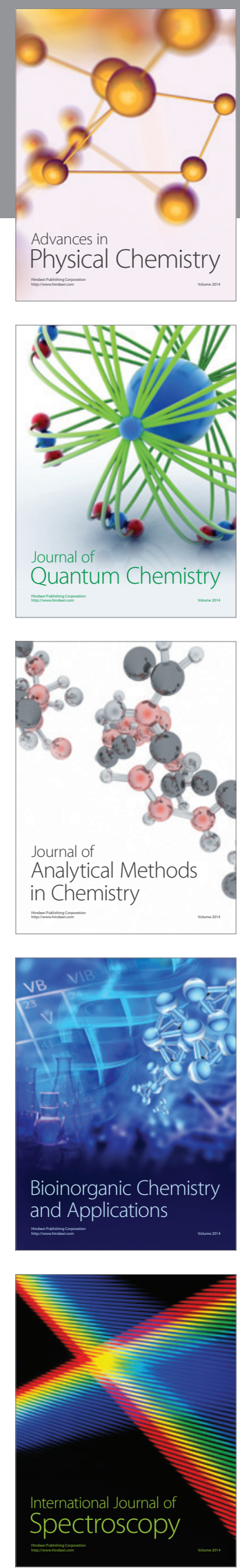